\title{
Identidad y ciudadanía afrocolombiana en la Región Pacífica y Cali: elementos estadísticos y sociológicos para el debate de la "cuestión negra” en Colombia
}

Olivier Barbary

Héctor Fabio Ramírez

Fernando Urrea

\section{Resumen}

El debate público en torno de las minorías étnicas en Colombia se reanudó recientemente a partir de la evolución jurídica y política importante marcada por la nueva Carta Magna del país (1991). Con el reconocimiento del carácter pluriétnico y cultural de la sociedad y la institucionalización del multiculturalismo en la constitución de la ciudadanía, Colombia, como muchos otros países latinoamericanos, intenta redefinir por completo el espacio y la condición de las poblaciones indígenas y afroamericanas en la sociedad mestiza.. En este contexto, el presente trabajo pone en evidencia la importancia del factor migratorio y de la urbanización masiva de la población afrocolombiana, en las dinámicas de construcción de nuevas 'identidades étnicas' y de reivindicación ciudadana, y en su diferenciación según los contextos locales y regionales. Aprovechando dos fuentes estadísticas -el censo de 1993, para la región del Pacífico, y una encuesta demográfica realizado en Cali en 1998-, las cuales se analizaron por medio de regresiones logísticas, así como datos cualitativos socioantropológicos, se llevó a cabo la interpretación sociológica de las determinaciones recíprocas entre el contexto territorial, económico y social en el cual se encuentra esta población, y los niveles y modalidades de la auto afirmación de una 'identidad afrocolombiana'. 
La conclusión principal es que las formas de afirmación de identidad son radicalmente diferentes para la población de la región pacífica y la población de Cali. Se trata en el primer caso de una reivindicación étnico territorial, mientras en el segundo, lo que está en juego es el acceso en igualdad de oportunidades a los mercados residenciales y laborales, y la denuncia de la discriminación socioracial. A la luz de estos resultados, el problema de la adecuación del marco jurídico de la Ley 70 con las necesidades y aspiraciones a la integración ciudadana de la población afrocolombiana, se coloca en nuevos términos, particularmente en la sociedad urbana.

Palabras claves: regiones de poblamiento negro, identidad negra, modelo "étnico-territorial", modelo de reivindicación "socio-racial", segregación residencial, "ghetto", percepción de discriminación socio-racial, "raza" y clase social, Colombia.

\section{Abstract \\ Afro-Colombian identity and citizenship in the Pacific region and Cali: statistic and sociological elements to the "black issue" debate in Colombia}

Public discussion on ethnic minorities in Colombia it began again recent through the important juridical and political evolution traced by the new Colombian Constitutional Law of 1991. With the recognition of multi-ethnic and cultural diversity character of the Colombian society, and the multiculturalism institutionalization in the citizenship formation, Colombia, like many others Latin-American countries, is looking for to change the space and the condition of Indians and Afro-American populations into the mestizo society. In this context, this work highlights the importance of the migratory factor and the Afro-Colombian population's massive urbanization, in the process of construction of new "ethnic identities" and the citizenship demand, and its differentiation according to regional and local contexts. Taking advantage of two statistics sources - the 1993 census, of the Pacific region, and a demographics research held up in Cali on 1998 -, in which were analyzed by logistics regressions, so as social anthropologic qualitative data, it was done the sociologically interpretation of the reciprocal determinations among territorial, economics and social contexts, in which can be found this population, and the many levels and modalities of self-affirmation of an "Afro-Colombian identity". The main conclusion is that identity affirmation forms are radically different to the Pacific region population and Cali's population. The first case is 
about an ethnic-territorial demand, whereas the second one what is at stake is the equality of opportunities to residential and labor markets, and the fight against social-racial discrimination. Considering these results, the problem of accommodating the forensic mark of Law 70 to the needs and aspirations of the citizen's integration of the Afro-Colombian population, is in new terms, particularly in the urban society.

Keywords: Regions of black settlement, black identity, "ethnical-territorial" model, model of "social-racial" claims, residential segregation, ghetto, social-racial prejudice feeling, "race”, social class, Cali, Colombia.

\section{Résumé}

Identité et citoyenneté afro-colombienne dans la région du Pacifique et à Cali: des données statistiques et sociologiques pour traiter la "question noire ", en Colombie

Le débat public autour des minorités ethniques en la Colombie il y a recommencé récemment dû à l'évolution juridique et politique très important repéré par la nouveau Carte Constitutionnelle de la Colombie (1991). Avec le reconnaissance du caractère pluriethnique et multiculturelle de la société, et l'institutionnalisation du multiculturalisme dû la constitution de la citoyenneté, la Colombie, comme autres pays de l'Amérique latine, cherche une redéfinition du espace et la condition des populations indiennes et afro-colombiennes dans la société métisse. D'accord au contexte antérieur, cet article met en relief l'importance du facteur migratoire et de l'urbanisation massive de la population afro-colombienne, dans la dynamique de la construction de nouvelles "identités ethniques" et de revendication de la citoyenneté, par rapport à ses différentes formes, selon qu'il s'agit du contexte local ou régional. À partir de deux types des données statistiques - celles du recensement de 1993, pour la région du Pacifique, et celles d'une recherche démographique qu'il y a été effectuée à Cali, en 1998 - on il y fait ici des analyses à travers des régressions logistiques -, aussi bien que sur des données qualitatives socio-antrophologiques. Cela il y a permis d'arriver à l'interprétation sociologique des interpénétrations entre le contexte territorial, économique et social où se trouve cette population, et des niveaux et des modalités de l'auto affirmation d'une identité afro-colombienne. Alors, il est possible constater que les formes d'affirmation de l'identité entre la population du sud Pacifique et celle de Cali sont radicalement opposées. Dans le premier cas, il s'agit d'une 
revendication ethnique-territoriale; dans le second, ce qui est en cause est l'accès aux marchés du logement et du travail, à parts égales, ainsi que la dénonciation de la discrimination socio-raciale. Sous l'éclairage de ces résultats, le problème de l'adéquation entre le point de repère juridique de la Loi no 70 et les besoins, les aspirations à l'intégration à la ville de la population afro-colombienne est placé sous un nouveau approach, tout particulièrement dans la société urbaine.

Mots-clés: régions de peuplement noir, identité noire, modèle de revendication "socio-raciale", ségrégation par le lieu de résidence, ghetto, perception de discrimination socio-raciale, " race ", classe sociale, Cali, Colombie. 


\section{Introducción}

Hacia una perspectiva contemporánea de la cuestión negra en Colombia

Ta nueva Constitución de Colombia (1991) reconoce en su dad y, con varias disposiciones jurídicas concretas, institucionaliza el multiculturalismo en las relaciones Estado-ciudadanos y hasta en el fundamento de la ciudadanía. En este contexto, el caso de la población afro-descendiente es, a la vez, particularmente significativo y problemático. Significativo, en primer lugar, debido a su importancia demográfica que, según varias fuentes estadísticas recientes, se sitúa en aproximadamente $20 \%$ y $22 \%$ de la población total del país, lo que equivale entre 8,6 y 9,5 millones de personas. ${ }^{1}$ Significativo también porque la cuestión de su condición social actual, aún marcada por las herencias de la esclavitud y de la sociedad colonial (exclusión territorial, marginalización social, económica y política), vuelve a surgir en primer plano del debate democrático, en términos bastante renovados por los avances constitucionales. Problemático, en segundo lugar, pues la "invisibilidad histórica” de la población negra en Colombia, combatida por los pioneros de los estudios afrocolombianos y sus sucesores (De Friedemann, Arocha, para citar algunos de los más sobresalientes), dio lugar a una producción científica caracterizada, hasta hace muy poco, por el indigenismo, el ruralismo y un cierto culturalismo, de la cual se aprecia, con el tiempo, toda la influencia que ejerció en las decisiones del legislador, pero que se revela insuficiente para entender la totalidad de las implicaciones contemporáneas. ${ }^{2}$ Así, la nueva movilización social y política de las poblaciones afrocolombianas, ${ }^{3}$ que se produce en un contexto geográfico, económico y social profundamente modificado por la rápida integración de los "territorios tradicionales" afrocolombianos a la economía global y por la urbanización masiva de estas poblaciones, se fundamenta en dos reivindicaciones, las cuales conllevan cierta tensión: por una 
parte, el respeto de una especificidad ecológica, económica y cultural, y de otra, el derecho de acceso, en igualdad de oportunidades, a los distintos mercados (vivienda, educación, trabajo, consumo, etc.). En el estado actual, la Ley privilegia claramente el primero de estos dos derechos.

\section{Recuadro 1}

Indigenismo, ruralismo y estudios afrocolombianos: premisas de la Ley de Negritudes

La tradición de los "estudios afrocolombianos" se ha caracterizado por el análisis de las poblaciones negras como grupo social homogéneo y relativamente estable a partir de atributos culturales diferenciados respecto al conjunto de la población colombiana, especialmente en la región de la Costa Pacífica, el municipio de San Basilio, próximo a Cartagena, y en las islas de San Andrés y Providencia. Son estudios en áreas rurales con actividades de minería de aluvión, pesca, agricultura, silvicultura; ninguno relacionado en espacios y actividades urbanas. Los ejes analíticos de estos trabajos se apoyan en las tradiciones antropológicas del difusionismo y culturalismo anglosajón, pero también del cognitivismo antropológico de Bateson y del estructuralismo francés con Lévi-Strauss, entre los cuales sobresalen Velásquez (1953, 1957 y 1961); Gutiérrez de Pineda (1968); Motta (1975 y 1993); De Friedemann (1974, 1976, 1984, 1985, 1986, 1993, 1998); Arocha (1989, 1992, 1999). Otros trabajos de intelectuales negros (Zapata Olivella, 1975) han combinado el ejercicio literario con descripciones antropológicas sobre usos y costumbres. Un tema importante en estos estudios ha sido la familia negra como modelo de organización cultural diferente a otros modelos de familia en Colombia, al igual que formas de "pensamiento" y organización social. Algunos de ellos han enfatizado los elementos de las tradiciones africanas en las poblaciones negras colombianas, como factor que las diferencia del resto. En cambio, difícilmente estos trabajos han orientado la mirada sobre las dinámicas culturales y las transformaciones sociales que viven desde hace varias décadas las poblaciones negras colombianas en el contexto de los procesos de modernización, y más recientemente de "globalización". 
Con la Ley 70 de 1993 o Ley de Negritudes (precedida por el Transitorio 55, resultado de la nueva constitución) surge la noción de comunidades negras, entendida como un grupo de pobladores en un territorio determinado (de la Costa Pacífica y las islas de San Andrés y Providencia) que pueden comprobar una ancestralidad afrocolombiana de varias generaciones atrás, residiendo en ese territorio. De esta manera se construye, muy similarmente a la noción de grupo étnico indígena, una nueva identidad de tipo étnico-territorial, con un componente racial o fenotípico secundario, para la cual importa presentar las pruebas de tener ancestros que siempre han habitado el lugar. El carácter "afro" de la comunidad con ancestros se apoya sobre la descendencia de los pobladores negros procedentes del África entre los siglos XVI y comienzos del XIX, que en el caso colombiano venían en su totalidad como esclavos. A partir de este aporte de población, múltiples generaciones con diversos grados de mestizaje, antes y después de la abolición de la esclavitud en 1851, habitaron esos territorios hasta el presente.

Desde 1996, el CIDSE y el IRD desarrollan conjuntamente un programa de investigación pluridisciplinaria y regional sobre las condiciones de inserción económica y social de las poblaciones negras del sudoeste colombiano, y las dinámicas demográficas, culturales y políticas recientes que actúan en diferentes espacios de la región del Pacífico, en la sociedad colombiana contemporánea (ver mapa 1 en la presentación del número de la revista). A Apoyándose en los resultados de este programa, este articulo explora las relaciones y las determinaciones recíprocas existentes entre estas dinámicas y los niveles y modalidades de la afirmación identitaria y de la percepción de las discriminaciones socio-raciales por parte de los actores en Cali. A partir de lo anterior proponemos algunas hipótesis sociológicas para explicar la emergencia de una reivindicación específica de acceso a la ciudadanía en las poblaciones negras.

En el contexto de la nueva legislación y las demandas de los movimientos negros en Colombia, durante la década del noventa se ha construido el término de población afrocolombiana. Con este término que usaremos a lo largo del artículo, nos estamos refiriendo a las poblaciones contemporáneas de descendientes de africanos con diversos grados de mestizaje a lo largo de varios siglos (ver Recuadro 1). En nuestro caso este término tiene una utilidad 
exclusivamente descriptiva, sin que nos preocupe el problema de ancestralidad cultural o los lazos de origen con los primeros africanos, lo cual nos permite hacer equivalentes poblaciones negras o mulatas y afrocolombianas. Esto significa que la dirección analítica nuestra tiene que ver más con las dinámicas culturales y sociales históricas y contemporáneas de estas poblaciones en la sociedad colombiana.

En la primera parte, el examen general de los resultados de la cuestión étnica incluida en el censo nacional de 1993 permite introducir el contexto histórico y contemporáneo particular en el cual se vuelve a plantear, desde la nueva Constitución de 1991, la cuestión de la identidad afrocolombiana. En la segunda parte, se presentan los datos estadísticos y el marco teórico de su análisis e interpretación sociológica. La tercera parte confronta un modelo logístico de las respuestas a esta pregunta en la región del Pacífico, territorio histórico del poblamiento negro en Colombia y espacio crucial de aplicación de la Ley 70, con los resultados de la investigación antropológica sobre el proceso social de construcción de una identidad afrocolombiana. Los resultados permiten comprobar la validez regional del modelo de identidad étnico-territorial propuesto por la Ley. En la cuarta parte, el mismo método aplicado a los datos recogidos en Cali, metrópoli de atracción de los flujos migratorios de la región del Pacífico, muestra que este modelo desaparece y da lugar a un juego más complejo de determinación de la identidad negra en reacción a las percepciones colectivas del fenotipo y a los motores sociales y raciales de discriminación. De esta manera, se pone en evidencia el efecto de la dinámica urbana sobre las identidades afrocolombianas teniendo en cuenta que hoy en día, al igual que el resto de la población colombiana, el $70 \%$ de los afrocolombianos residen en áreas urbanas.

\section{La pregunta étnica del censo de 1993: un fracaso a escala} nacional... muy heuristico

$\mathrm{Al}$ introducir una pregunta étnica a escala nacional en el censo - y después de muchas discusiones internas - el DANE creó grandes expectativas en las comunidades indígenas y afrocolombianas y en los gremios científicos. ${ }^{5}$ En la mayoría de los casos, fue de igual magnitud la decepción cuando salieron los resultados nacionales y en las grandes ciudades: las etnias indígenas representan el $1,6 \%$ de la población total del país y las comunidades negras el 
1,5\%, mientras en Bogota, Cali y Medellín, como en la mayoría de las ciudades importantes del país, estos dígitos son inferiores al 0,2\% para cada una de las poblaciones (DANE, 2000:61-72, 4. Resultados). En el conjunto de la población de Cali, por ejemplo (Cuadro 1), las personas mayores de edad (18 años o más) que contestaron "si" a la pregunta fueron solamente el $0.5 \%$, mientras el $95.5 \%$ contestó que "no" y el $4 \%$ se negó a responder. Todavía más extraño: en poblaciones de inmigrantes a Cali nacidos en las regiones donde domina el poblamiento negro y mulato (franja del Pacífico y Norte del Cauca) o indígena y mestizo (interior de los Departamentos del Cauca y Nariño), las respuestas afirmativas no crecen significativamente: el máximo, alcanzado por los nativos del Chocó, sólo es de 2,6\%, cuando Urrea, Ramírez y Viáfara (2002) estiman a 83\% la proporción de población afrocolombiana en este departamento. El resultado paradójico del Censo de 1993 es que la población afrocolombiana a nivel nacional termina siendo inferior a la de los grupos indígenas: 502.393 versus 532.233 personas (DANE: 2000:18).

Cuadro 1

Distribución de Respuestas a la Pregunta Étnica del Censo, según Lugares de Nacimiento de las Personas Censadas en Cali

\begin{tabular}{|c|c|c|c|c|c|c|c|c|c|c|c|}
\hline $\begin{array}{c}\text { Regiones } \\
\text { de naci- } \\
\text { miento }\end{array}$ & Cali & $\begin{array}{c}\text { Cost } \\
\text { Pac. } \\
\text { Nariño } \\
\end{array}$ & $\begin{array}{l}\text { Cost } \\
\text { Pac. } \\
\text { Cauca } \\
\end{array}$ & $\begin{array}{l}\text { Cost } \\
\text { Pac. } \\
\text { Valle } \\
\end{array}$ & Chocó & $\begin{array}{c}\text { Nort. } \\
\text { del } \\
\text { Cauca }\end{array}$ & $/ \ldots$ & $\begin{array}{l}\text { Otros } \\
\text { Cauca }\end{array}$ & $\begin{array}{c}\text { Otros } \\
\text { Nariño }\end{array}$ & $\begin{array}{c}\text { Antioq. } \\
\text { V. Caldas }\end{array}$ & Total \\
\hline SI & 0,32 & 1,67 & 1,22 & 1,35 & 2,63 & 1,29 & & 0,92 & 0,43 & 0,28 & 0,49 \\
\hline NO & 95,97 & 93,82 & 94,66 & 94,61 & 92,93 & 94,63 & & 94,93 & 95,68 & 95,65 & 95,45 \\
\hline NO RESP & 3,71 & 4,51 & 4,13 & 4,04 & 4,43 & 4,07 & & 4,15 & 3,89 & 4,07 & 4,06 \\
\hline Total \% & 100 & 100 & 100 & 100 & 100 & 100 & & 100 & 100 & 100 & 100 \\
\hline Observ. & 882.124 & 33.232 & 18.805 & 22.764 & 13.018 & 28.272 & & 57.883 & 36.849 & 148.972 & 1.661 .433 \\
\hline
\end{tabular}

Fonte: Barbary y Ramirez (1997:7).

Sin embargo tales dígitos, que muchos consideraron surrealistas, no deben sorprender. Volver operacional una noción tan vaga e inestable, como es la de pertenencia étnica, dentro de un formato censal administrado por encuestadores con capacitación necesariamente rápida a una población sumamente heterogénea, se convirtió en un reto prácticamente imposible. En primer lugar, el empleo de la palabra "etnia", inusual y mal comprendida por una gran parte de la población, no dio el resultado esperado. Pero más allá de un problema de formulación, los factores histórico y sociológico son probablemente de mayor importancia. A diferencia de los Estados Unidos, cuya tradición estadística inspiró clara- 
mente esta pregunta (véase Simón, 1998:14-21), Colombia no es un país donde haya existido, después de la abolición de la esclavitud, una segregación racial institucionalizada. Tampoco es un país donde los movimientos etnopolíticos, como los derechos civiles en EE.UU. o la lucha anti-apartheiden Sudáfrica, hayan tenido un largo desarrollo histórico. En dichos países la segregación, herencia del pasado o resultado de las problemáticas actuales (incluyendo la "affirmative action"), ha trazado en lo político, lo jurídico, lo social y, por supuesto, en el interior de las conciencias colectivas, los hitos de una profunda división racial de la sociedad. La "etnicización institucional", para llamarlo de alguna manera, no es comparable en la historia o el presente colombiano; en consecuencia, tampoco son comparables los niveles de la identidad étnica.

Así, los resultados del censo demuestran que no existe en la sociedad colombiana de hoy, por lo menos en el medio urbano, un sentimiento de comunidad étnica compartido y libremente declarado por grupos significativos de la población, en particular la gente negra y mulata. Ahora bien, si en su propósito principal, que era medir el peso demográfico de las minorías étnicas a nivel nacional, la experiencia del censo fue un fracaso, los resultados son completamente distintos a escala local. Es el caso, en particular, para la región del Pacifico, con una tasa promedia de respuesta positiva del $44 \%$ y fuertes variaciones según subregiones y localidades. Tales datos ofrecen entonces la oportunidad de analizar en detalles, como lo haremos en la sección 3, los factores determinantes (históricos y geográficos, económicos y sociales, etc.) de la variabilidad de respuesta. Volviendo a Cali, los dígitos del cuadro no significan que no haya discriminación socio-racial o que las personas estigmatizados como "negros" o "indios" sean en una proporción tan reducida; son simplemente la constancia de que un tal enfoque de corte étnico no permite captar en la ciudad, las nuevas percepciones e identidades sociales y culturales en torno a "lo negro". En esta misma dirección se observa que en Cali, durante las dos últimas elecciones de alcalde y concejales (1998 y 2000), época en la que ya existía una amplia gama de organizaciones afrocolombianas en la ciudad y el Departamento del Valle, los candidatos negros que se lanzaron a nombre de causas de las "negritudes" y trataron de movilizar a la población negra en los barrios donde se da su mayor concentración, usando de una argumentación "comunitaria", tuvieron escasa votación. ${ }^{6}$ 
2. Variaciones de la afirmación de una "identidad negra": datos, métodos e hipótesis

Ya que con el censo de 1993 y la encuesta CIDSE/IRD de 1998 se disponía de dos corpus de respuestas a preguntas de auto-percepción étnica y fenotípica, ${ }^{7}$ la ocasión era propicia para poner en relación estas respuestas, por un lado, con las variables socio-demográficas individuales que estas dos fuentes nos suministran (sexo, edad, nivel de educación, categoría socio-profesional), y por el otro, con ciertos descriptores del contexto en el cual éstas son enunciadas: localización geográfica de la residencia, tamaño de la localidad, zona de residencia y estatuto migratorio de los individuos encuestados en Cali. Este segundo grupo de variables permite acceder, a través de la bibliografía, a los contextos regionales y locales y a sus dinámicas política y cultural, factores de los que se puede pensar tienen una influencia importante. Por último, en el caso de la encuesta realizada en Cali, también se cuenta con otras dos variables potencialmente determinantes: el fenotipo de los individuos observado por el encuestador y las características del mismo encuestador (sexo y fenotipo).

¿Cómo se articula este conjunto de factores para explicar las variaciones de la auto-percepción étnica en la región de poblamiento negro del sudoeste colombiano ${ }^{8}$ y de la auto-percepción del color de piel entre la población afrocolombiana de Cali? ¿A qué hipótesis nos puede llevar este análisis respecto al proceso de construcción de una afirmación identitaria negra en Colombia? ¿Qué diferentes formas puede adoptar este proceso según los contextos en los cuales se expresan los actores y según sus características individuales o colectivas?

El instrumento estadístico escogido para contestar estas preguntas es la regresión logística. Ella se aplicará a las frecuencias de las variables dependientes dicotómicas (respuestas) observadas cuando se cruzan con las variables explicativas (regresores, ver recuadro 2).

En el caso de Cali, al lado de los resultados estadísticos, los datos cualitativos de encuestas antropológicas permiten la aproximación de las mediaciones simbólicas entre los sujetos: cómo se autopercibe la gente negra en el barrio donde reside y cómo es percibida desde fuera, desde los "otros barrios". Es decir, bajo qué formas concretas, incluso a nivel lexical, se elabora la separación entre unos barrios y otros, de manera que simbólicamente, en algunas dimensiones de la vida cotidiana, se construye la segregación so- 


\section{Recuadro 2}

Regresiones logísticas sobre dos tipos de afirmación de una "identidad negra"

1. RESPNEG (pregunta étnica del censo de 1993): Se codifican con "SI" las personas que contestaron que pertenecen a una "comunidad negra".

2. RSPNEGRA (pregunta sobre el color de piel en la encuesta CIDSE/IRD): Se codifican con "SI" las personas cuya respuesta contiene el adjetivo "negralo", sólo o en una frase afirmativa.

\section{VARIABLES EXPLICATIVAS}

- Características individuales generales: sexo, edad, nivel educativo, categoría socio-profesional

- Características especificas de la encuesta Cidse/Ird: fenotipo del individuo observado por el encuestador, sexo y fenotipo del encuestador

- Variables contextuales (censo DANE 1993): localización geográfica y tamaño del municipio de residencia

- Variables contextuales (Cidse/Ird, 1998): zona de residencia en Cali y condición migratoria del individuo

Las regresiones que presentamos aquí estiman, por el método del máximo de verosimilitud, los valores de los parámetros correspondientes a cada uno de los efectos incluidos en la ecuación log-lineal del modelo (efectos principales de las variables explicativas consideradas como independientes unas de otras, o efectos cruzados de las modalidades de varias variables). Esta ecuación expresa el logaritmo de la frecuencia de respuesta positiva (probabilidad empírica) como una función lineal del conjunto de los logaritmos de las frecuencias de modalidades explicativas. El signo del parámetro estimado caracteriza el efecto de determinación de la respuesta: favorable si el parámetro es positivo, desfavorable si es negativo. A cada parámetro está asociada una prueba de significatividad (y un intervalo de confianza) que mide la importancia estadística del efecto. Los procedimientos utilizados aquí son LOGISTIC y CATMOD, del software SAS, con pruebas basadas en el ${ }^{x^{2}}$ de Wald (1943). Desafortunadamente, esta versión de SAS no permite tomar en 
cuenta el diseño de la muestra; dado que la prueba es muy sensible a los tamaños de la muestra, para la encuesta CIDSE/IRD hemos utilizado los datos sin ponderarlos por los factores de expansión.

cio-espacial. A pesar de que las modalidades empíricas de la segregación en Cali no sean similares a las que existen en otras ciudades o en otras sociedades, aparecen expresiones semánticas que atraviesan fronteras nacionales, procediendo de contextos sociales muy distintos. Es el caso de la palabra "ghetto", actualmente reapropiada y resignificada por parte de los jóvenes para enunciar en términos émicos la segregación residencial.'

Apoyada, como se verá en las secciones siguientes, en ambos tipos de información estadística y antropológica, nuestra principal hipótesis se dirige a mostrar que además de los factores socio-políticos, los contextos socio-geográficos urbanos y rurales son determinantes en la producción de las identidades étnico-raciales. Si concebimos la identidad como una manera de hacer visible, de parte del sujeto que la comporta, una subjetividad personal inscrita en algo más colectivo, entonces los espacios urbanos, sobre todo en las grandes ciudades, como productores de individualidades, las más de las veces fragmentadas, no tienen mucho que ver con sentimientos de communitas, de pronto más propios de los medios rurales. Mientras en las áreas rurales es posible la existencia relativamente estable de comunidades "de origen", en la ciudad ya no es viable eso por la inevitable dispersión. Si bien existen en Cali barrios con alta concentración de población negra de un mismo origen (Charco Azul, El Retiro, Mojica, Valladito, etc.), incluso con miembros de la misma red familiar residiendo en manzanas próximas o en la misma calle (Urrea, Arboleda, Arias, 2000), esta concentración barrial no garantiza la formación de una comunidad, en términos sociológicos, ya que es más fuerte la dinámica urbana de separación entre los espacios residencial, laboral, lúdico, etc., de la vida cotidiana, en fin la dinámica de generación de nuevas amistades y relaciones micro. Aquí, en lugar de un asentamiento "rural", con diferencias relativamente moderadas, aparecen redes sociales de familias y paisanos con profundas diferencias intergeneracionales y sociodemográficas, habitando a veces los mismos barrios, pero donde pueden registrarse estadística y etnográficamente condiciones de vida desiguales. La sociedad urbana 
como espacio de modernización y de vivencias modernas impone la dinámica de la individualización y fragmentación de la vida social, fenómeno que ya fue advertido por los clásicos de la sociología urbana, en particular por G. Simmel.

\section{Un modelo "étnico-territorial" eficiente en el Pacífico}

La pregunta étnica del censo de 1993 capta bien, en la región de poblamiento negro del Pacífico, el nivel general y las variaciones locales de la afirmación de pertenencia a la comunidad negra. En la totalidad de la población mayor de 18 años de esta región, la frecuencia de respuestas positivas es del $44,5 \%$ y sufre muy fuertes variaciones locales: del 3\% en el municipio de Buenaventura (costa Pacífica del Valle), pasa al $27 \%$ en la costa Pacífica de Nariño, al $71 \%$ en la del Cauca, a mas de $80 \%$ en el conjunto de municipios del sur y centro del Chocó, incluyendo la capital, Quibdó, hasta superar el 95\% en el norte de este departamento (Mapa 1). Frente a estas variaciones espaciales, la tentación existe de relacionarlas con las dinámicas locales de emergencia de las nuevas identidades étnicas o neo-étnicas que acompañan el movimiento social de las "comunidades negras" y sus implicaciones económicas y territoriales: este movimiento surgió precisamente en Quibdó y en la zona rural del norte del Chocó a finales de los años ochenta y condujo, justo antes del censo, a la adopción de la Ley 70.

La regresión logística confirma ampliamente la hipótesis de una relación fuerte entre los dos procesos. En el modelo completo de los efectos principales, los seis parámetros correspondientes a las variables consideradas independientemente unas de otras (sexo, edad, nivel de educación, categoría socio-profesional, tamaño de la localidad y región de residencia) son todos significativos (Cuadro 2). ${ }^{10}$ Sin embargo, el efecto del contexto regional (captado a través de "la región de residencia") domina ampliamente todos los demás, con una parte de variabilidad de las respuestas explicada diez veces superior a los dos efectos siguientes: la categoría socio-profesional y el tamaño de la localidad. En comparación, los efectos del sexo y del nivel de educación aparecen despreciables (más de cincuenta veces inferiores). Así, siendo iguales los demás factores, los habitantes de un municipio del norte del Chocó tienen una probabilidad de respuesta positiva 3,5 veces mayor que los de la costa Pacífica del Nariño, mientras que en Buenaventura dicha probabilidad es 4 veces inferior. El rol de la categoría so- 
Identidad y ciudadanía afrocolombiana en la Región Pacífica y Cali...

Tasas municipales de autopercepción de pertenencia a las comunidades negras en la región del Pacifico (censo de población de 1993)

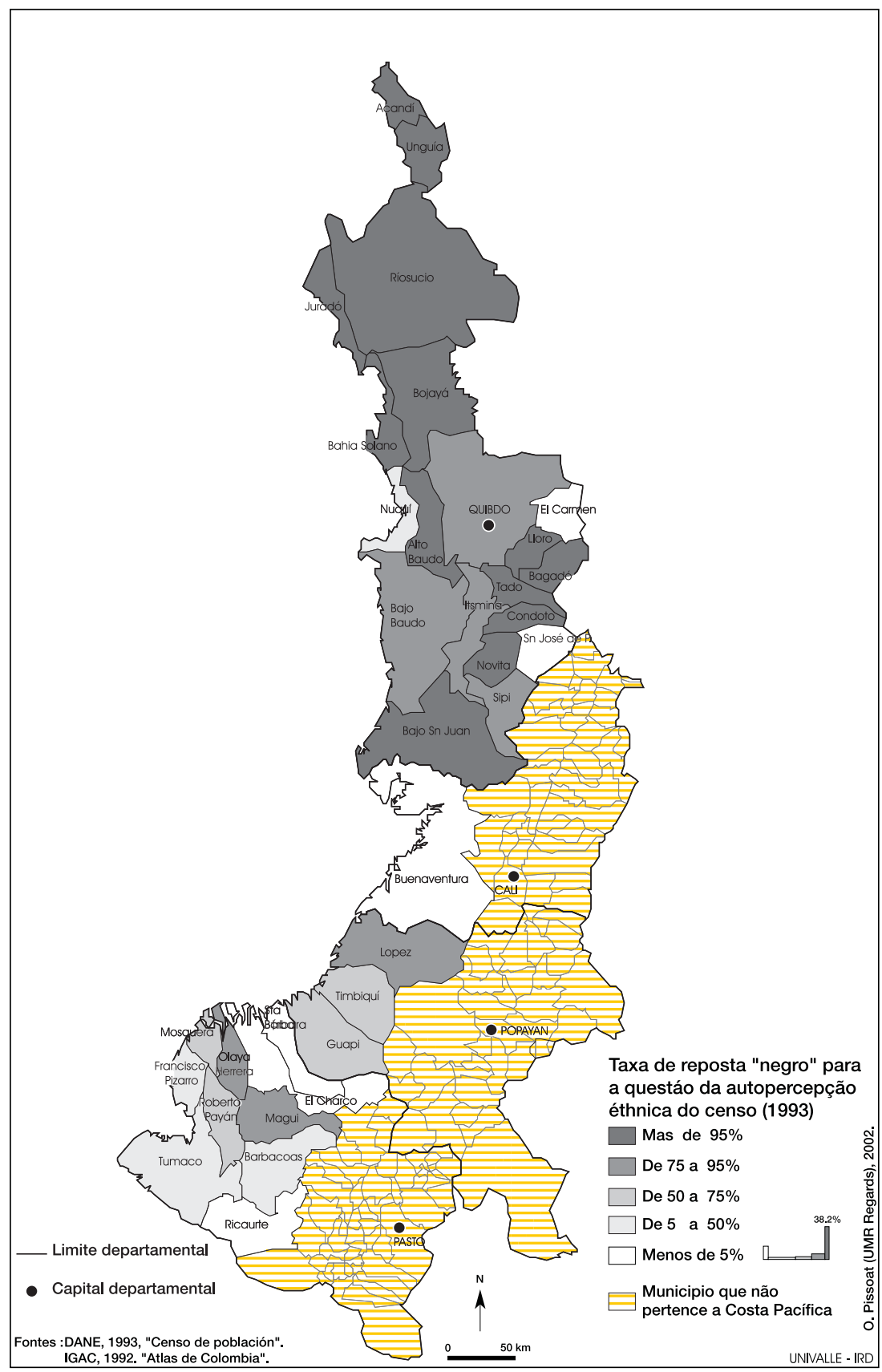


cio-profesional es igualmente claro: éste opone los trabajadores independientes o familiares de la agricultura, la pesca y la minería (efecto positivo, en particular en el sector minero donde la probabilidad se multiplica por 2,5) a los obreros, empleados o patronos de todos los sectores (probabilidad disminuida en aproximadamente 5 a $10 \%)$.

\section{Cuadro 2}

Modelo logístico para las respuestas a la pregunta étnica del censo 1) Análisis de varianza

$\begin{array}{lrcr}\text { Variables } & \text { Grad. Lib. } & \text { Chi-cuadrado } & \text { Probabilidad } \\ \text { Intercept } & 1 & 0.41 & 0.5237 \\ \text { Sexo } & 1 & 80.08 & 0.0000 \\ \text { EdadY } & 2 & 209.26 & 0.0000 \\ \text { NivEduY } & 5 & 1294.58 & 0.0000 \\ \text { SociOcup } & 16 & 6693.06 & 0.0000 \\ \text { TamLocal } & 4 & 5052.80 & 0.0000 \\ \text { RegioRes } & 5 & 57650.91 & 0.0000 \\ \text { Likelihood-Ratio } & & 19750.29 & 0.0000\end{array}$

2) Estimación de los parámetros

\begin{tabular}{|l|r|l|c|c|c|}
\hline $\begin{array}{r}\text { Variables } \\
\text { Categoría de referencia }\end{array}$ & $\begin{array}{r}\text { Parámetro } \\
\text { estimado }\end{array}$ & $\begin{array}{l}\text { Nivel } \\
\text { Sign. }\end{array}$ & $\begin{array}{c}\text { Estima- } \\
\text { ción } \\
\text { Respuesta }\end{array}$ & $\begin{array}{c}\text { Residuos } \\
\text { (Obs-Est) }\end{array}$ & $\begin{array}{c}\text { Efecto } \\
\text { Marginal }\end{array}$ \\
\hline Constante & -0.00820 & 0.5237 & $49.8 \%$ & $-5.3 \%$ & \\
\hline Hombre & -0.0525 & 0.0000 & $25.5 \%$ & $-1.8 \%$ & $-2.1 \%$ \\
Mujer & 0.0525 & & $27.6 \%$ & $5.6 \%$ & \\
31-50 años & 0.00626 & 0.3662 & n.s. & n.s. & n.s. \\
Más de 50 años & -0.1044 & 0.0000 & $23.7 \%$ & $1.7 \%$ & $-3.9 \%$ \\
& 0.09814 & & $27.6 \%$ & $5.6 \%$ & \\
\hline Ninguno-no respuesta & 0.3710 & 0.0000 & $32.2 \%$ & $2.2 \%$ & $4.6 \%$ \\
Primaria completa & -0.1604 & 0.0000 & $21.8 \%$ & $2.0 \%$ & $-5.8 \%$ \\
Secundaria incompleta & -0.0536 & 0.0000 & $23.7 \%$ & $-1.9 \%$ & $-3.9 \%$ \\
Secundaria completa & -0.1148 & 0.0000 & $22.6 \%$ & $-5.2 \%$ & $-5.0 \%$ \\
Universit. post. & -0.1928 & 0.0000 & $21.2 \%$ & $1.0 \%$ & $-6.3 \%$ \\
\multicolumn{1}{|c|}{ Primaria incompleta } & 0.1506 & & $27.6 \%$ & $5.6 \%$ & \\
\hline Inactivos & 0.0961 & 0.0001 & $33.6 \%$ & $-13.6 \%$ & $6.0 \%$ \\
Estudiantes & 0.1648 & 0.0000 & $35.1 \%$ & $10.4 \%$ & $7.5 \%$ \\
Desempleados & -0.0997 & 0.0000 & $29.3 \%$ & $-10.4 \%$ & $1.8 \%$ \\
Empleados Domest & -0.3742 & 0.0000 & $24.0 \%$ & $-10.3 \%$ & $-3.6 \%$ \\
O/E Sec Descon & -0.1681 & 0.0000 & $27.9 \%$ & $-5.7 \%$ & $0.4 \%$ \\
\hline
\end{tabular}


Identidad y ciudadanía afrocolombiana en la Región Pacífica y Cali...

\begin{tabular}{|l|r|c|c|c|c|}
\hline O/E Ag-Pe-Mi-C-T & -0.5120 & 0.0000 & $21.6 \%$ & $0.5 \%$ & $-6.0 \%$ \\
O/E Manu-E-Com-S & -0.4247 & 0.0000 & $23.1 \%$ & $-11.6 \%$ & $-4.5 \%$ \\
O/E Fin-I-Gob-Ed & 0.00113 & 0.9590 & n.s. & n.s. & n.s. \\
Pos Des Ag-Pe-Mi & 0.3415 & 0.0000 & $39.2 \%$ & $7.5 \%$ & $11.7 \%$ \\
\hline Pos Des Otros Se & 0.0162 & 0.5338 & n.s. & n.s. & n.s. \\
Ind-Fam Sect Des & 0.3187 & 0.0000 & $38.7 \%$ & $0.5 \%$ & $11.1 \%$ \\
Ind-Fam Agr-Pesc & 0.3445 & 0.0000 & $39.3 \%$ & $25.4 \%$ & $11.7 \%$ \\
Ind-Fam Mineria & 1.4624 & 0.0000 & $66.4 \%$ & $-3.3 \%$ & $38.9 \%$ \\
Ind-Fam Otros Se & -0.1917 & 0.0000 & $27.5 \%$ & $-13.2 \%$ & $-0.1 \%$ \\
Patrón Ag-Pes-Mi & -0.3769 & 0.0000 & $23.9 \%$ & $9.4 \%$ & $-3.6 \%$ \\
Patrón Otros Sec & -0.4110 & 0.0000 & $23.3 \%$ & $76.7 \%$ & $-4.2 \%$ \\
\multicolumn{1}{|c|}{ Oficios del hogar } & -0.18703 & & $27.6 \%$ & $5.6 \%$ & \\
\hline Urb<=5.000 pers & -1.1882 & 0.0000 & $6.2 \%$ & $-6.2 \%$ & $-21.3 \%$ \\
$5000<$ Prb<=50000 & 0.8757 & 0.0000 & $34.4 \%$ & $12.8 \%$ & $6.8 \%$ \\
50000<urb<=100000 & -0.0173 & 0.3795 & $n . s$. & $n . s$. & $n . s$. \\
Urbano>100.000 & -0.2254 & 0.0000 & $14.8 \%$ & $-3.8 \%$ & $-12.7 \%$ \\
& 0.5552 & & $27.6 \%$ & $5.6 \%$ & \\
\hline Pacífico Cauca & 0.1087 & 0.0000 & $68.3 \%$ & $-8.2 \%$ & $40.8 \%$ \\
Pacífico Valle & -3.3417 & 0.0000 & $6.4 \%$ & $-2.8 \%$ & $-21.1 \%$ \\
Sur del Choco & 0.6512 & 0.0000 & $78.8 \%$ & $-9.2 \%$ & $51.2 \%$ \\
Centro del Choco & 1.0507 & 0.0000 & $84.7 \%$ & $-6.9 \%$ & $57.2 \%$ \\
Norte del Choco & 3.1589 & 0.0000 & $97.9 \%$ & $-0.2 \%$ & $70.3 \%$ \\
\hline
\end{tabular}

Respecto al tamaño de la localidad, el modelo con interacciones de orden 2 muestra que su efecto propio desaparece ante los efectos cruzados con la categoría socio-profesional y la región de residencia, poniendo así de relieve los nichos sociales y geográficos de mayor afirmación étnica: empleados domésticos, obreros y empleados de las manufacturas, del comercio y los servicios, residentes en las aldeas de menos de 5.000 habitantes (en especial en la costa Pacífica del Cauca), trabajadores independientes o familiares de la explotación minera en estas mismas aldeas, pero sobre todo en las pequeñas ciudades de 5.000 a 50.000 habitantes del Chocó. En este modelo, hay que señalar finalmente la fuerte afirmación étnica de los habitantes del norte de Chocó que poseen un nivel de educación superior (probabilidad prácticamente duplicada en relación con el nivel de educación primaria incompleta), cuyo papel se conoce como determinante, desde su movilización 
en la fase preparatoria de los debates de la Asamblea Constituyente, ${ }^{11}$ hasta las instancias actuales del movimiento de "comunidades negras", pasando por la discusión de la Ley 70 entre los años 1991 y 1993, a través del mecanismo llamado Transitorio 55 que ordena la misma Asamblea Constituyente.

Conviene entonces situar la interpretación de estas diferencias en el contexto "neo-comunitarista" que enmarca el nacimiento político de la nueva "identidad afrocolombiana". Agier y Quintín subrayan, en su artículo de esta revista, al respecto que

es a partir de las políticas desarrollistas aplicadas a la región, así como de una revalorización, a escala mundial (pero retomada localmente por las organizaciones no gubernamentales y por la misma Iglesia Católica y por el Estado), de los discursos que reivindican el regionalismo, el localismo, la identidad étnica y la protección del medio ambiente, que la identidad afrocolombiana del Pacífico comienza a surgir de forma fuerte, en los escenarios políticos, aproximadamente a fines de los años ochenta e inicios de los noventa. (Agier y Quintín, 2000:68)

Pero además, en estas condiciones, el acceso al estatuto y a los subsidios previstos en la Ley 70 reposa en la generación de una identidad cultural y étnica ligada ante todo a un territorio (las regiones rurales de la costa Pacífica) y a un sistema económico de explotación de los recursos, cuyo núcleo es la microempresa familiar tradicional, basada en la combinación de actividades agrícolas, pesqueras y mineras (por lo demás muy amenazada. Cf. Hoffman, 2000 a y 2000b). Uno observa entonces sin mayor sorpresa que las poblaciones más directamente interesadas por este nuevo dispositivo jurídico buscan ceñirse lo más posible a la afirmación de una identidad neo-étnica que, de alguna manera, la Constitución les exige al mismo tiempo que les otorga. Con base en su estudio de Tumaco, Hoffmann (2000b:19) resume esta situación de la siguiente manera:

para las poblaciones rurales del Pacífico, la entrada a la modernidad pasa por la reivindicación -muchas veces la "invención" en el sentido antropológico- de la ancestralidad y del particularismo étnico. [...] El territorio es fundamento y base de la movilización en un doble sentido: por un lado legitima y condiciona el acceso a estos derechos nuevamente adquiridos después de siglos de "invisibilidad", y por el otro propicia la construcción de un nuevo actor colectivo de envergadura nacional -las comunidades negras- cuyo rango de acción puede, legalmente, abarcar muchas otras esferas de la vida pública, electoral, educación, investigación, planes de desarrollo, etc. 
Fuera de la región del Pacífico y de los territorios designados en la Ley 70 como propios de las comunidades negras, un modelo relativamente similar de afirmación etnico-territorial se observa en Puerto Tejada y en otras zonas del Norte del Cauca, el que ha sido objeto de estudios socio-antropológicos (Urrea y Hurtado, 1997; Hurtado, 2000; y Urrea y Hurtado, 2002). En el municipio de Puerto Tejada, el cual forma parte del área metropolitana de Cali, con una población asalariada, mayoritariamente negra, constituyendo su núcleo urbano una " ciudad dormitorio » de Cali, la nueva identidad negra expresada por movimientos sociales y políticos locales se basa en la exaltación nostálgica de la sociedad campesina negra vinculada al cultivo del cacao, el tabaco y café, dominante hasta los años cuarenta, en oposición a la gran plantación capitalista de caña de azúcar que se impone progresivamente en la región desde los años cincuenta, con la consiguiente proletarización de su población. Las pequeñas propiedades que aún sobrevivieron a la expansión del cultivo de la caña y que continúan en manos de pobladores negros son tomadas como ejemplo de resistencia y no son pocas las voces entre los grupos de jóvenes negros universitarios que residen en Puerto Tejada, para reclamar la extensión de la Ley 70 a esta región. El proyecto de comunidades negras basadas en la tierra colectiva, de la parte que se le expropió a una hacienda ganadera para la plobación negra en los años 80 , es reconstituir un pasado idílico (Urrea y Hurtado, 2002).

En esta fase del análisis surgen dos interrogantes. Primero, la población tomada en cuenta en este primer modelo no incluye solamente personas de ascendencia africana susceptibles de contestar afirmativamente a la pregunta, ya que estas últimas no son identificables en el censo. De allí se desprende que gran parte de las respuestas negativas a la pregunta del censo provienen de minorías blancas, indígenas y mestizas que no podemos excluir de la modelización, lo que evidentemente sesga la interpretación: en efecto, las mismas relaciones puestas en evidencia son sobredeterminadas por las estructuras geográfica, económica y social propias de la población de ascendencia africana. En otros términos, los datos censales en la región del Pacífico no permiten saber en qué medida la ascendencia africana condiciona allí igualmente, y quizá fuertemente, la afirmación de la pertenencia étnica. En segundo lugar, este enfoque asume implícitamente que las poblaciones negras y mulatas emigradas fuera del espacio geográfico amparado por la Ley 70, hoy en día mayoritarias, supuestamente deberían tener una afirmación neo-étnica al igual que la población negra del Pací- 
fico, lo cual como vimos no es cierto. Pero entonces ¿qué hay de los procesos de construcción de una identidad negra en la ciudad? Y si éstos existen, ¿̇en qué se fundamentan?

Ante todo, es importante señalar que a partir de la Constitución de 1991 y de la Ley 70 se impuso un modelo multiculturalista en Colombia, que incluyó las formas institucionales del gasto público. En ese sentido, se desarrollaron unidades administrativas especializadas en el interior del Estado colombiano, a escala nacional, departamental y municipal, para la atención de la problemática de las "minorías étnicas y negritudes". ${ }^{12}$ Por esta razón el gasto social desde el Estado, por lo menos en teoría, tiene una distinción también "étnica", aunque efectivamente las organizaciones indígenas han conseguido recursos en forma significativa por esta orientación, a diferencia de las organizaciones afrocolombianas, las cuales en su gran mayoría están ubicadas en los principales centros urbanos de Colombia.

\section{Un modelo de "reivindicación socio-racial" en Cali}

En la encuesta llevada a cabo en Cali, además de las variables ya consideradas en la modelización de los datos censales (sexo, edad, nivel de educación, categoría socio-profesional), se dispone de otras cuatro variables:

- la caracterización fenotípica del encuestado observada por el encuestador (4 modalidades: negro, mulato, blanco, mestizo y otro);

- las características del encuestador (4 modalidades: mujer negra o mulata, hombre negro o mulato, mujer blanca o mestiza, hombre blanco o mestizo);

- la zona de residencia en Cali (4 modalidades: barrios populares del este, barrios de clase media del peri-centro y del este, barrios populares de la periferia occidental, barrios residenciales del sur);

- la condición migratoria (15 modalidades elaboradas a partir del cruce del lugar de nacimiento -nativos de Cali vs. migrantes-y del lugar de origen entendido como la región de nacimiento de los migrantes o, en el caso de los nativos, de sus padres, eventualmente migrantes ${ }^{13}$ ).

La población para la cual se construye el modelo es el conjunto de personas de la muestra que tienen un fenotipo negro o 
mulato (observación del encuestador), mayores de 18 años y que hayan contestado la pregunta. Entre estas 1.256 personas, el $42 \%$ declararon ser de piel negra, y el 65\% si se agregan los adjetivos 'negra' y 'morena'.

En Cali, los contenidos semánticos de estos dos adjetivos son en general muy diferentes y dependen del contexto social en el que se emplean: el uso de "negro/a" por la población blanca o mestiza contiene con frecuencia (pero no siempre) una intención de estigmatización, explícita o no, mientras que la apelación eufemizante "moreno/a" es una categoría que pretende sistemáticamente evacuar todo contenido racial explícito, sobre todo cuando la persona que la utiliza no tiene ascendencia africana visible, y esto incluso en situaciones objetivas de discriminación racial. A los ojos de la mayoría de la población negra y mulata, "moreno/a" aparece a menudo como una forma paternalista de matizar o minimizar el estereotipo racista "negro/a". Este contexto explica por qué estas dos palabras pueden atestiguar afirmaciones "identitarias" opuestas cuando se enuncian en respuesta a la pregunta de auto-identificación fenotípica, según un esquema de inversión del estigma. De acuerdo con esta hipótesis, la respuesta "negra" correspondería en muchos casos a una reivindicación de pertenencia a la "comunidad de descendientes de africanos", en tanto que minoría históricamente discriminada, mientras que la respuesta "morena" puede interpretarse como una búsqueda de invisibilidad racial y una estrategia de "blanqueamiento". ${ }^{14}$ Algunos de los resultados de las pruebas estadísticas que vamos a presentar apuntan a pensar que así funciona. Sin embargo, desde la observación antropológica, hay que advertir que esto es válido sobre todo en aquellos contextos en donde la expresión "moreno/a", está asociada a cierta invisibilidad del factor racial: por ejemplo, en espacios de circulación por fuera de las áreas de residencia (en el mercado de trabajo, en lugares de consumos o espacios culturales más interraciales, etc.). Por otro lado, es también probable que la asociación de la respuesta "negro/a" a una pertenencia a la "comunidad de descendientes africanos" sea variable en el conjunto de la población negra; más frecuente en el seno de las organizaciones culturales negras, entre jóvenes con niveles educativos secundarios y universitarios o también en los círculos de profesionales negros de clases medias.

$\mathrm{El}$ análisis de las respuestas en las que se utiliza el adjetivo "negra/o", opuestas a las otras (variable RESPNEGRA), corresponde entonces a la prueba de la hipótesis según la cual estas res- 
puestas dan testimonio de una "afirmación socio-racial reinvidicativa". Tal elección de entrada para abordar el proceso de construcción de la identidad "negra" en Cali reposa, como se acaba de ver, en una interpretación semántica a priori de las respuestas, la cual orienta a su vez la interpretación sociológica; aun cuando ciertos datos antropológicos la sostienen, es importante ser consciente que ella no excluye en absoluto otras interpretaciones. ${ }^{15}$

El tamaño de muestra es insuficiente para armar un modelo completo con las ocho variables. El procedimiento LOGISTIC permite seleccionar las variables en el orden de su contribución a la "explicación" de la variabilidad total de las respuestas. Se conservan entonces cuatro variables, ya que las otras no superan el umbral de significatividad de $90 \%$, que son, en orden de importancia de los efectos: el fenotipo, la edad, la categoría profesional y la condición migratoria de los encuestados. La zona de residencia es determinante solamente cuando no se hace intervenir el fenotipo, lo que muestra una fuerte relación entre las dos variables y nos remite a la "especialización socio-racial" del espacio residencial en Cali, ya estudiada (cf. Barbary et alii, 1999b:37-41, 71-76; Barbary, 2001:6-8; Barbary, Ramírez, Urrea, 1999a:459, 475, 488 e 501).

El primer resultado notable es la ausencia de efectos importantes del sexo del encuestado y de las características del encuestador. En el conjunto de la muestra, existe un ligero efecto del sexo de los encuestados (significativo con probabilidad del 90\%) -teniendo las mujeres una probabilidad de declarar un color de piel negra superior en un $20 \%$ aproximadamente, frente a los hombres, pero no hay ningún efecto significativo de las características del encuestador. ${ }^{16}$ Por lo tanto, la relación encuestador/encuestado no reviste la importancia que se podía temer y que con frecuencia le atribuyen los antropólogos en sus críticas a este tipo de enfoque, enfatizando en lo que Agier y Quintín (op. cit.) llaman "el juego de roles goffmaniano entre el entrevistador y el entrevistado". Mas precisamente, si bien el modelo aporta algunos índices para sostener la existencia de un tal juego, nos lleva también la prueba que sus consecuencias estadísticas son extremamente limitadas. Eso indica claramente que el efecto micro de la relación encuestador/encuestado no es ajeno al contexto societal mayor en donde opera un orden clasificatorio racial implícito y " oculto » (no institucionalizado a diferencia de los países en donde ha existido el apartheid), que todos los individuos, en un menor o mayor grado dependiendo de muchos factores, practican cotidianamente. En la sociedad caleña, los habitus (en el sentido de Elias, 1991) de los di- 
ferentes grupos sociales tienen, en una gran medida, una matriz común de clasificación fenotípica de los cuerpos. De ahí que los estereotipos raciales operen como un dispositivo social de distinción que clasifica a los individuos por su apariencia física.

El modelo que conserva las cuatro variables más determinantes muestra un desempeño bastante bueno, tanto para prever las respuestas individuales ( $74 \%$ de exactitud) como para estimar las frecuencias de respuesta de las diferentes categorías de población. ${ }^{17}$ Analizando la determinación de las respuestas por las características individuales, es el efecto del fenotipo el que predomina ampliamente, explicando entre 5 y 30 veces más variabilidad que los otros tres caracteres (cuadro 3). Así, siendo iguales los demás factores, las personas de fenotipo negro tienen una probabilidad de declarar un color de piel negra aproximadamente cuatro veces superior a las personas de fenotipo mulato. Sin embargo, este modelo conduce igualmente a rechazar la hipótesis de independencia entre las variables; hay que interesarse, en particular, en las interacciones entre el fenotipo, el origen migratorio, la categoría profesional y la zona de residencia. Siendo demasiado reducida la muestra para modelizar las interacciones de orden superior a 2, nos limitaremos a los modelos saturados con dos variables, que cruzan el fenotipo con las otras tres (Cuadro 4).

Respecto a los efectos del origen geográfico y de la edad, los resultados consignados en los dos cuadros conducen a conclusiones opuestas en relación con la afirmación étnica en la región del Pacífico. En Cali, la única región de origen que favorece de manera significativa la afirmación de un color de piel negra es la costa Pacífica del Cauca. Más aún, el coeficiente significativo no es el que corresponde a los migrantes nacidos en la región, sino el de sus descendientes nacidos en Cali (probabilidad dos veces superior al promedio). En cambio, conforme a la lógica, los descendientes de migrantes de orígenes distantes de las zonas de influencia demográfica y cultural negra, como es el caso del interior de los departamentos del Valle, Cauca y Nariño y de los otros departamentos de Colombia, la declaran significativamente menos (probabilidad reducida en más de un tercio en relación con el promedio). El resto de la variabilidad de las respuestas según el origen migratorio no debe atribuirse al origen propiamente dicho, sino más bien a las variaciones de composición fenotípica de las poblaciones. Así, contrariamente a lo que se esperaba teniendo en cuenta la afirmación masiva, en el censo, de pertenencia a la comunidad negra por parte de los habitantes del Chocó, las personas oriundas de este de- 
partamento encuestadas en Cali no declaran más un color de piel negra, en condiciones de fenotipo, profesión y edad iguales, que las personas de otros orígenes. Por último, el efecto del origen difiere a veces según el fenotipo. Es el caso para los migrantes de la costa Pacífica del departamento de Nariño, sus descendientes nacidos en Cali y los migrantes de Buenaventura, entre los cuales las personas caracterizadas como "negras" declaran relativamente menos un color de piel negra que para otros orígenes, mientras que, al contrario, las personas caracterizadas como "mulatas" la declaran relativamente más. En cuanto a la edad, ésta juega en sentido inverso al modelo anterior en el que se observaba una sub-declaración moderada pero significativa entre las personas mayores de 50 años; en este caso, son los jóvenes entre 18 y 30 años quienes afirman ligeramente menos un fenotipo negro que las personas mayores.

\section{Cuadro 3}

Efectos significativos de cuatro variables sobre las respuestas a la pregunta “¿Cuál es su color de piel?”" (modelo logístico sobre 1.256 personas de fenotipo negro o mulato, mayores de 18 años)

\begin{tabular}{|c|c|c|c|c|c|}
\hline Variables & $\begin{array}{l}\text { Categorias significativas } \\
\text { con probabilidad de: } \\
* * * 99 \% ; * * 95 \%, * \\
90 \%\end{array}$ & $\begin{array}{c}\text { Valor } \\
\text { estimado } \\
\text { parámetro }\end{array}$ & $\begin{array}{c}\text { Nivel } \\
\text { de Sign. } \\
\text { (prob) }\end{array}$ & $\begin{array}{c}\text { Frecuencia } \\
\text { marginal } \\
\text { estimada }\end{array}$ & $\begin{array}{c}\text { Frecuencia } \\
\text { marginal } \\
\text { observada }\end{array}$ \\
\hline CONSTANTE & & -0.6090 & 0.0000 & $35 \%$ & $42 \%$ \\
\hline FENOTIPO & Negro $(+)^{* * *} \quad r$ & $\begin{array}{r}1.0383 \\
-1.0383 \\
\end{array}$ & 0.0000 & $\begin{array}{l}61 \% \\
16 \% \\
\end{array}$ & $\begin{array}{l}57 \% \\
12 \% \\
\end{array}$ \\
\hline EDAD & $\begin{array}{r}18-30 \text { años }(-)^{* *} \\
\text { más de } 50 \text { años }\end{array}$ & $\begin{array}{r}-0.2343 \\
0.1768 \\
\end{array}$ & 0.0275 & $\begin{array}{l}30 \% \\
39 \%\end{array}$ & $\begin{array}{l}38 \% \\
43 \%\end{array}$ \\
\hline $\begin{array}{l}\text { CAT. } \\
\text { OCUPAC. }\end{array}$ & $\begin{array}{l}\text { Otros Asal Serv (-)* } \\
\text { Maest obr Manuf }(+)^{* *} \\
\text { Desempleados }(-)^{*} \\
\text { Inactivos }\end{array}$ & $\begin{array}{r}-0.4516 \\
0.6334 \\
-0.4567 \\
-0.3709\end{array}$ & $\begin{array}{l}0.0751 \\
0.0169 \\
0.0599\end{array}$ & $\begin{array}{l}26 \% \\
51 \% \\
26 \% \\
27 \% \\
\end{array}$ & $\begin{array}{l}38 \% \\
55 \% \\
34 \% \\
33 \% \\
\end{array}$ \\
\hline $\begin{array}{l}\text { COND. } \\
\text { MIGRAT. }\end{array}$ & \begin{tabular}{|} 
Nac Ca Orig Pac \\
Cauca-Patia $(+)^{* *}$ \\
Nac Ca Orig Norte del \\
Cauca $(-)^{*}$ \\
Nac Ca Orig Int. \\
Va., Cau.,Na $(-)^{* * *}$ \\
Mig Otros $(-)^{* *}$ \\
$\quad \mathrm{Nac}$ Ca O Otros
\end{tabular} & $\begin{array}{l}1.5522 \\
-0.5346 \\
-0.7234 \\
-0.6819 \\
-0.5149\end{array}$ & $\begin{array}{l}0.0120 \\
0.0733 \\
0.0074 \\
0.0149\end{array}$ & $\begin{array}{l}72 \% \\
24 \% \\
20 \% \\
22 \% \\
24 \%\end{array}$ & $\begin{array}{r}73 \% \\
36 \% \\
19 \% \\
21 \% \\
19 \%\end{array}$ \\
\hline
\end{tabular}




\section{Cuadro 4}

Efectos cruzados sobre las respuestas a la pregunta “¿cuál es su color de piel?” (modelos logísticos con interacciones sobre 1.256 personas)

\begin{tabular}{|c|c|c|c|c|c|}
\hline Variables & $\begin{array}{l}\text { Categorias } \\
\text { significativas } \\
\text { con } \\
\text { probabilidad } \\
\text { de: } \\
* * * 99 \% ; * * \\
95 \%, * 90 \%\end{array}$ & $\begin{array}{r}\text { Valor } \\
\text { estimado } \\
\text { parámetr } \\
\text { o }\end{array}$ & $\begin{array}{l}\text { Nivel de } \\
\text { Sign. } \\
\text { (prob) }\end{array}$ & $\begin{array}{l}\text { Frecuenci } \\
\quad \text { a } \\
\text { marginal } \\
\text { estimada }\end{array}$ & $\begin{array}{c}\text { Frecuencia } \\
\text { marginal } \\
\text { observada }\end{array}$ \\
\hline \multicolumn{6}{|c|}{ Fenotipo y condición migratoria, con interacción } \\
\hline CONSTANTE & & $-0,8776$ & 0.0000 & $29 \%$ & $42 \%$ \\
\hline FENOTIPO & $\begin{array}{l}\text { Negro }(+)^{* * *} \\
\text { Mulato }\end{array}$ & $\begin{array}{r}1,2675 \\
-1,2675 \\
\end{array}$ & 0.0000 & $\begin{array}{l}60 \% \\
11 \% \\
\end{array}$ & $\begin{array}{l}57 \% \\
12 \% \\
\end{array}$ \\
\hline $\begin{array}{l}\text { COND. } \\
\text { MIGRAT. }\end{array}$ & $\begin{array}{l}\text { Nac Cali } \\
\text { Orig Cali (-) } \\
* * * \\
\text { Nac Ca Orig } \\
\text { Pac } \\
\text { Cauca-Patía } \\
(+)^{* * *} \\
\text { Nac Ca Orig } \\
\text { Int. } \\
\text { Va.,Cau., Na } \\
(-)^{* *} \\
\text { Mig Otros } \\
(-)^{* *} \\
\end{array}$ & $-0,4223$ & 0.0019 & $65 \%$ & $21 \%$ \\
\hline FENOTIPO $\times$ & $\begin{array}{l}\text { Negro Mig } \\
\text { Pac Nariño } \\
(-) * * *\end{array}$ & $-0,7215$ & 0.0034 & $54 \%$ & $54 \%$ \\
\hline $\begin{array}{l}\text { COND. } \\
\text { MIGRAT. }\end{array}$ & $\begin{array}{l}\text { Negro Nac } \\
\text { Ca Orig Pac } \\
\text { Nariño (-) } \\
* * * \\
\text { Negro Mig } \\
\text { Pac Valle (-) } \\
* *\end{array}$ & $-0,6893$ & 0.0177 & $57 \%$ & $57 \%$ \\
\hline \multicolumn{6}{|c|}{ Fenotipo y categoría ocupacional, con interacción } \\
\hline CONSTANTE & & $-1,0808$ & 0.0000 & $25 \%$ & $42 \%$ \\
\hline
\end{tabular}


Olivier Barbary, Héctor Fabio Ramírez e Fernando Urrea

\begin{tabular}{|c|c|c|c|c|c|}
\hline FENOTIPO & $\begin{array}{l}\text { Negro }(+)^{* * *} \\
\text { Mulato }\end{array}$ & $\begin{array}{r}1,3982 \\
-1,3982 \\
\end{array}$ & 0.0000 & $\begin{array}{c}58 \% \\
8 \% \\
\end{array}$ & $\begin{array}{l}57 \% \\
12 \% \\
\end{array}$ \\
\hline CAT. OCUP & $\begin{array}{l}\text { Maest obr } \\
\text { Manuf }(+)^{*} \\
\text { Ayu } \\
\text { ArtConstrsp } \\
(+)^{*}\end{array}$ & $\begin{array}{l}0,6552 \\
0,4748\end{array}$ & $\begin{array}{l}0.0538 \\
0.0880\end{array}$ & $\begin{array}{l}40 \% \\
35 \%\end{array}$ & $\begin{array}{l}55 \% \\
45 \%\end{array}$ \\
\hline FENOTIPO $\times$ & $\begin{array}{l}\text { Negro Secr, } \\
\text { Pers admin } \\
(-)^{* *}\end{array}$ & $-0,6806$ & 0.0268 & $50 \%$ & $50 \%$ \\
\hline CAT. OCUP & $\begin{array}{l}\text { Negro Maest } \\
\text { Artesanos (-) } \\
\text { ** } \\
\text { Negro Ayu } \\
\text { ArtConstrsp } \\
(-) \text { ** }\end{array}$ & $\begin{array}{l}-0,6680 \\
-0,5690\end{array}$ & $\begin{array}{l}0.0247 \\
0.0409\end{array}$ & $48 \%$ & $48 \%$ \\
\hline \multicolumn{6}{|c|}{ Fenotipo y zona de residencia en Cali, con interacción } \\
\hline CONSTANTE & & $-1,0087$ & 0.0000 & $27 \%$ & $42 \%$ \\
\hline FENOTIPO & $\begin{array}{l}\text { Negro }(+)^{* * *} \\
\text { Mulato }\end{array}$ & $\begin{array}{r}1,132 \\
-1,132 \\
\end{array}$ & 0.0000 & $\begin{array}{l}53 \% \\
11 \% \\
\end{array}$ & $\begin{array}{l}57 \% \\
12 \% \\
\end{array}$ \\
\hline ZONA RESID & $\begin{array}{l}\text { Barr. Pop } \\
\text { Orien }(+)^{*} \\
\text { Barr. Pop } \\
\text { Lader (-) }\end{array}$ & $\begin{array}{c}0,2342 \\
-0,7716\end{array}$ & $\begin{array}{l}0.0980 \\
0.0061\end{array}$ & $\begin{array}{l}32 \% \\
14 \%\end{array}$ & $\begin{array}{l}46 \% \\
15 \%\end{array}$ \\
\hline
\end{tabular}

Las categorías socio-profesionales no juegan, en la afirmación del fenotipo en Cali, el rol determinante que ejercen sobre la afirmación de la pertenencia a la comunidad negra en la región del Pacífico. Al umbral de confianza del 95\%, sólo los obreros calificados de la industria tienden a declarar con mayor frecuencia un color de piel negra (probabilidad 1,8 veces superior a la de la población inactiva). Para ciertas categorías profesionales, tales como el secretariado y el personal administrativo, los artesanos o el personal no calificado del artesanado, de la construcción y del transporte, la declaración de un color de piel negra depende nuevamente del fenotipo: las personas caracterizadas como "negras" la declaran con una frecuencia ligeramente menor que en las otras categorías laborales. Finalmente, los barrios populares de invasión en las laderas de la Cordillera Occidental, donde la proporción de población caracterizada como 'negra' es la más baja (menos del 3\% contra el $15 \%$ en promedio), constituyen la única zona de residencia 
en Cali que ejerza tal vez un efecto propio sobre la respuesta: en esta zona, a igual fenotipo, la probabilidad de declararse de piel negra se divide por dos. ${ }^{18}$

\section{Dos modelos diferentes de etnicidad}

El modelo identitario propuesto por la Ley tiene indiscutiblemente un impacto importante en la región del Pacífico, capaz de producir localmente, tal como lo hemos mostrado, un sentimiento masivo de pertenencia colectiva a las "comunidades negras". De lo anterior se puede concluir, que en Cali la autoafirmación fenotípica de las poblaciones afrocolombianas funciona de una manera radicalmente diferente. Sus variaciones no siguen un principio estructurante único, contrariamente al papel que desempeñan en la afirmación neo-étnica en el Pacífico las dinámicas sociopolíticas locales, causas o consecuencias de la Ley 70. En la ciudad, la construcción de la identidad "negra" aparece a la vez más compleja y endógena en su elaboración, ante todo en estrecha relación con las categorías raciales de uso común (tanto émicas como utilizadas por los encuestadores), las divisiones y las fronteras que ellas suponen, así como los estigmas, o en forma opuesta, las connotaciones positivas que ellas producen en diferentes contextos. Es necesario primero anotar que la fuerte correlación estadística entre la autopercepción del color de piel y la caracterización externa del fenotipo se explica a partir de un cierto consenso ambiguo entre diversos tipo de usos, tanto "discriminatorios" como "neutrales" de esas categorías "raciales". Como evidencia, la denominación "negro/a" en Cali-y probablemente en los otros contextos urbanos colombianos-, a pesar de su uso más general estigmatizante, no conlleva siempre y en todas partes subentendidos racistas explícitos; en algunas situaciones su empleo corresponde a maneras intimistas que no tienen carácter despectivo.

Nos parece igualmente claro que el color de piel y, más ampliamente, la percepción del fenotipo, se colocan en una especie de interacción con otras características, tales como el origen migratorio, la edad, la categoría socio-ocupacional, el lugar de residencia o el sexo, para producir y determinar la construcción social de la alteridad y sus consecuencias en términos de segmentación, si no segregación, de los espacios y de los mercados urbanos. La "raza", en el sentido que nosotros le damos de categoría fenotípica percibida e interpretada, eventualmente de modo racista, en las interaccio- 
nes sociales, es entonces uno de los ingredientes de la "fábrica de las lógicas sociales". Desde esta perspectiva, más que una hipotética transferencia de una identidad étnico-territorial, adquirida a través de la región de origen, el proceso de construcción de la identidad "negra" urbana nos parece que corresponde ante todo a la necesidad de enfrentar, en tanto que ciudadanos (as) sometidos a diferentes tipos de discriminación -o que perciben dicho riesgo-, las desigualdades de acceso a los mercados de trabajo, la educación, el sistema de salud, el consumo, etc., en suma, a una reivindicación por la igualdad de oportunidades. Para desarrollar más esta hipótesis vamos ahora a retomar el análisis de las respuestas sobre opiniones en torno a la discriminación en la encuesta CIDSE-IRD.

\section{La percepción de las discriminaciones socio-raciales en Cali}

Los comentarios que siguen se apoyan en los resultados de regresiones logísticas aplicadas a las preguntas sobre la existencia de discriminaciones raciales en diferentes contextos en Cali y en las declaraciones de experiencias personales de discriminación de parte de los encuestados (Recuadro 3).

\section{Recuadro 3 \\ Regresiones logísticas sobre la percepción de discriminaciones sociales y raciales}

En esta segunda serie de modelos logísticos las variables analizadas son las frecuencias de respuestas positivas a las preguntas sobre la existencia de discriminaciones raciales en distintos contextos y sobre experiencias personales de discriminación. Son un total de ocho variables dicotómicas: discriminación de la gente negra en hospitales y centros de salud, en escuelas y colegios, en transportes colectivos, en entidades de la administración publica, por la policía, en el barrio y, finalmente, ocurrencia de una experiencia personal de discriminación. Los modelos se aplican sucesivamente al conjunto de la muestra de la encuesta (1880 personas), y luego a la submuestra de personas caracterizadas negras o mulatas por los encuestadores (1256 personas). Buscamos los determinantes de estas respuestas dentro 
del mismo conjunto de variables individuales que para la auto-afirmación del color de piel. Para las siete primeras respuestas se investiga también en qué medida ellas dependen de las experiencias personales de discriminación. Simétricamente, para esta última respuesta, el modelo incluye como variables independientes las siete primeras respuestas. Los parámetros correspondientes a los diferentes modelos, demasiado numerosos, no son reproducidos aquí pero, por supuesto, el comentario se fundamenta en ellos. Además, como apoyo a nuestra argumentación, el cuadro 5 presenta las frecuencias de respuestas positivas observadas según el fenotipo y el sexo del individuo.

Los resultados, a pesar de ser interesantes, tienen calidades de predicción inferiores al del modelo de afirmación del color de piel. ${ }^{19}$ Pero si las opiniones sobre discriminación racial son en su conjunto un poco menos ligadas a los factores sociodemográficos que la afirmación del fenotipo, hay sin embargo una muy fuerte coherencia en los esquemas de determinación de los dos tipos de respuestas; veamos al respecto cuatro ejemplos.

1. La regresión confirma lo que muestran las frecuencias de la tabla (Cuadro 5): la declaración de una experiencia personal de discriminación, como la autopercepción del color de piel, está ante todo ligada al fenotipo. En el conjunto de la muestra, las personas caracterizadas "negras" por los encuestadores tienen, siendo iguales los demás factores y de modo extremamente significativo, una probabilidad muy superior de declarar una experiencia de discriminación (32\% versus $20 \%$ en promedio). Entre las poblaciones negra y mulata, la diferencia de probabilidad es casi del doble: $32 \%$ versus $17 \%$. Por supuesto, hay que distinguir la declaración de la ocurrencia real y se puede así objetar que la calificación discriminatoria de tal o cual episodio es un asunto de percepción personal. Sin embargo, no hay duda que esta relación entre fenotipo observado por los encuestadores y la ocurrencia de episodios discriminatorios prueba que existe en Cali, como ocurre en muchas otras partes, un substrato racista afectando una serie de contextos de la vida social. 


\section{Cuadro 5}

Respuestas afirmativas a las preguntas de opinión sobre la discriminación, según la caracterización fenotípica y el sexo de los encuestados (diferencias significativas observadas)

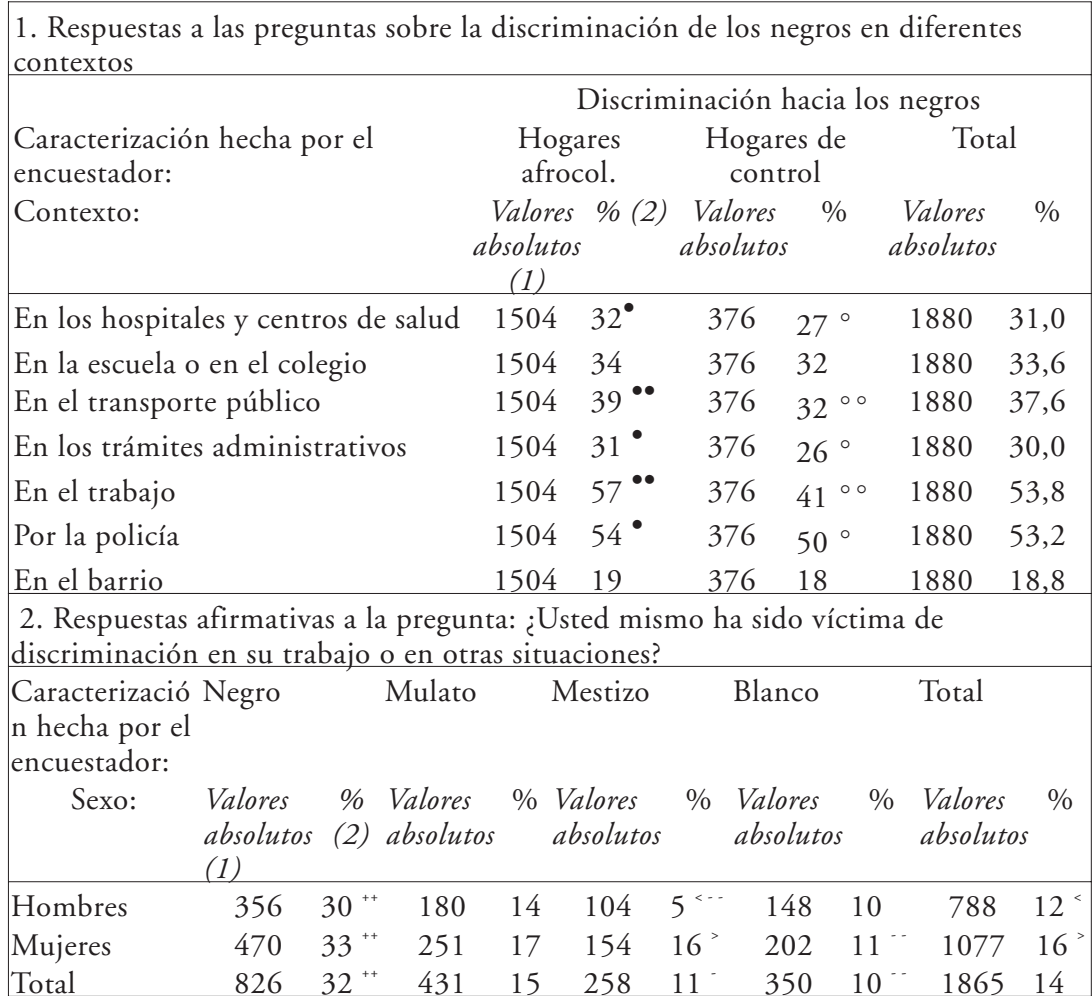

Fuente: encuesta CIDSE/IRD junio 1998

(1) Los valores absolutos corresponden a las personas que respondieron la pregunta.

Debido al reducido número de casos, las categorías "indígenas" y "otros" fueron excluidas de las tablas.

(2) Las frecuencias corresponden a las respuestas afirmativas, estimadas a partir de la muestra sobre el conjunto de la población de 18 años y más; los datos han sido ponderados por los factores de extrapolación del muestreo. El test de significatividad está basado sobre los intervalos de confianza a los niveles de $95 \%$ y $99 \%$, asociados al diseño muestral, con las siguientes anotaciones:

$>$, $>$ et $<$, $<$ : Diferencias positivas $(>,>)$ y negativas $(<,<)$ entre sexos, significativas con probabilidades del $95 \%(>,<)$ y $99 \%(>,<)$

,+++ et,,--- : Diferencias positivas $(+,++)$ y negativas $(-,--)$ para la categoría fenotípica, en relación al promedio de la muestra.

$\bullet, \cdots$ et ${ }^{\circ},{ }^{\circ}$ : Diferencias positivas $\left(\bullet^{\bullet}, \bullet\right.$ ) y negativas $\left({ }^{\circ},{ }^{\circ}\right)$ para el tipo de hogar, en relación al promedio de la muestra. 
2. Según la opinión de los encuestados, después del color de piel, el origen migratorio es el primer determinante "sociodemográfico" de la discriminación en casi todos los contextos (con excepción de los hospitales y centros de salud y en el barrio). Se observan en efecto diversas asociaciones estadísticas, las cuales varían según los contextos de la relación social (escuela, trabajo, transportes, etc.), entre la percepción de la discriminación y el origen geográfico de los encuestados o de sus padres. En síntesis, una especie de gradiente de exposición al racismo se dibuja: él parte de un nivel mínimo para los migrantes de la Costa Pacífica del Cauca (en casi todos los contextos) y los migrantes del Norte del Cauca y sus descendientes nacidos en Cali (contextos de trabajo, policía), luego se acentúa con los migrantes del Chocó (contexto de trato en la administración pública y privada) y del interior del Valle, Cauca y Nariño (contexto de transporte) y los nativos de Cali originarios de la Costa Pacífica de Nariño (contexto escolar), para llegar a su máximo nivel en los migrantes de Buenaventura y sus descendientes nacidos en Cali (contextos de transportes, trabajo, policía, sistema escolar). Como veremos más adelante, este gradiente corresponde a unas dinámicas regionales diferenciadas, en términos de procesos socio-raciales locales.

3. Los otros factores determinantes de las opiniones respecto a la existencia de racismo varían según los contextos en donde se produce el evento. La población de los barrios residenciales del Sur (clases medias y altas) es más sensible a las discriminaciones en el sistema escolar de primaria y secundaria, en los procedimientos administrativos y los transportes (las probabilidades aumentan de 15 a 30\%); al contrario, los habitantes de las áreas pobres de la periferia occidental denuncian mucho menos esas discriminaciones (la probabilidad se reduce en aproximadamente 15\%). Sin que cause sorpresa, las discriminaciones por parte de la policía golpean sobre todo a los jóvenes (entre 18-30 años) y las categorías profesionales expuestas a controles policíacos (comerciantes ambulantes y de plazas de mercado, trabajadores de los transportes). La misma lógica de exposición explica las variaciones de percepción en los transportes: frecuencias más elevadas para las categorías móviles (asalariados de los servicios, obreros manufactureros) que en el caso de los inactivos o las empleadas domésticas. El caso de la percepción del racismo en el barrio es particular, primero porque su nivel promedio es bajo (solamente 19\% de respuestas afirmativas), segundo porque sus variaciones según el fenotipo son a la inversa del esquema observado en los otros contextos (las personas 
caracterizadas negras las perciben ligeramente menos que las personas blancas), y tercero, sobre todo porque aparece claramente la colusión entre estigmatización social y racial. En efecto, tanto para el conjunto de la población como para la población negra y mulata, las frecuencias de percepción aumentan fuertemente entre los desempleados (35\%) y los estatus socio-profesionales menos estables (trabajadores no calificados de tipo artesanal, de la construcción y los transportes: $31 \%$ ), mientras que son particularmente débiles para los patronos artesanales y los obreros calificados manufactureros (15\%). Así, a pesar de la referencia explícita a la discriminación de la gente negra, las discriminaciones percibidas en el barrio parecen más relacionadas con la exclusión de las categorías sociales marginales que con manifestaciones propiamente racistas. Nos confrontamos de nuevo aquí ante el fenómeno de la inequidad "socio-racial", sobre el cual volveremos para interpretar estos resultados.

4. La percepción de los problemas de discriminación encontrados en el medio escolar se inscribe en un contexto que se hace indispensable recordar. El profundo atraso y pérdida de calidad del sistema educativo en la primaria y secundaria colombiana, principalmente debido al desplome de la enseñanza pública por causa de las políticas del Estado que favorecen al sector privado con desinterés por la educación pública, al igual que los altos costos de la educación privada (la que puede llegar a ser de aceptable calidad para los estratos socioeconómicos medios y altos o de pésimo rendimiento en los estratos bajos), en la coyuntura de recesión actual (particularmente crítica en Cali), constituye uno de los principales frenos a la reducción de la inequidad social. De modo progresivo, la carga financiera para los hogares de cualquier estrategia de acceso a un capital escolar valorizable en el mercado de trabajo, termina siendo insoportable para el conjunto de las clases populares y la mayor parte de las clases medias. Esto se convierte en el factor principal de una exclusión económica masiva por el desempleo o el subempleo, conllevando una involución considerable en la historia social del país. En este contexto, la existencia de discriminaciones hacia la población afrocolombiana en la escuela o colegio es denunciada por una tercera parte de los encuestados de la encuesta de Cali, sin diferencia significativa de percepción entre la población afrocolombiana considerada en su conjunto y el resto de la población (ver cuadro 5). La regresión logística coloca en evidencia tres factores de variaciones importantes. 
- Al igual que los otros tipos de discriminación, la percepción de las discriminaciones escolares aumenta significativamente en las personas que declaran un color de piel negro y en las personas que han reportado una experiencia personal de discriminación. El análisis de las respuestas abiertas que describen las situaciones de discriminación escolar muestra que, para las personas más expuestas de la muestra, la existencia de una inequidad racial en el acceso a la educación no tiene duda alguna. En las entrevistas realizadas por Urrea y Quintín (2000) a jóvenes negros, hombres y mujeres, de los barrios populares y de "invasión" al Oriente de la ciudad, la evocación de la estigmatización socio-racial se conjuga con la ausencia de opción de movilidad social ofrecida por la educación, sobretodo en las escuelas públicas pero también en las privadas. Esta desvalorización de la educación permite explicar las impresionantes tasas de deserción escolar en estos barrios, sobre todo entre los adolescentes.

- El grupo entre 31-50 años se inquieta más por este problema que los mismos jóvenes (18-30 años) que lo sufren o que las personas de más de 50 años. Se observa así una mayor sensibilidad de los adultos encargados de los hogares, quienes en el contexto de la profunda crisis del sistema escolar tienen mayor conciencia de la gravedad de la situación.

- A través de las variaciones significativas según el nivel educativo, el lugar de residencia en Cali y el origen geográfico, aparece un gradiente sociocultural de percepción. Así, las personas que tienen un nivel de estudios universitarios, siendo iguales los demás factores, tienen una frecuencia de declaración muy superior a las que no tienen educación primaria $(+64 \%)$; de igual manera, los residentes de los barrios de clases medias y altas en relación con los de los barrios pobres $(+30 \%)$. En fin, en el interior de la población caracterizada como negra o mulata, los migrantes de la Costa Pacífica del Cauca tienen una probabilidad de declaración inferior a la mitad del promedio, mientras que los nativos de Cali -de padres originarios de la Costa Pacífico de Nariño-, los migrantes de Buenaventura y los del interior de los Departamentos del Valle, Cauca y Nariño se distinguen por las altas percepciones (superiores entre un 30 y $40 \%$ al promedio). No es entonces sorprendente que 
las clases medias negras y mulatas, que han efectuado su migración a Cali con una perspectiva de ascenso social, si no para ellos mismos al menos para sus hijos, y a menudo han pagado un alto precio para educarlos, sean las más sensibles a este asunto.

El conjunto de estos resultados debe interpretarse evocando al menos tres clases de factores distintos (culturales, socioeconómicos y residenciales). Como se verá enseguida, cada uno de ellos, considerado separadamente, no permite dar cuenta del conjunto de las diferencias observadas en la percepción de la discriminación, sino sus efectos combinados que ilustran entonces la imbricación de los motivos sociales y raciales de la discriminación. Esto nos pone frente a la complejidad de las puestas en juego y las determinaciones de la identidad "socio-racial" en Cali.

1. Se puede proponer primero unas explicaciones de orden geográfico e histórico, según el tipo de relaciones sociales y raciales que han caracterizado a las sociedades locales de origen y que pesan sobre las condiciones "culturales" de la inserción urbana. La Costa Pacífica del Cauca y del Norte del Cauca son regiones en donde el poblamiento negro, a pesar de ser antiguo y dominante en términos demográficos, no dio lugar a la constitución de sociedades "negras" tan encerradas, ya sea en el plano económico o cultural, como en la Costa Pacífica de Nariño o el Chocó. El mestizaje, la interdependencia, incluso muy desigual, en los planos económico, político y cultural, respecto a la sociedad blanca y mestiza local, la influencia constante de centros urbanos del interior del país como Popayán y Cali (Urrea y Hurtado, 1997), han creado en las poblaciones una práctica y una memoria de la coexistencia interracial que, de algún modo, aportaron al orden socio-racial dominante hoy en día en Cali. Recíprocamente, la imagen del "negro (a)" existe en Cali desde los orígenes de la ciudad, cuando era un simple villorrio, y en toda la región del valle geográfico del río Cauca, debido precisamente a que Cali y esta región fueron centros de la hacienda esclavista minero-ganadera que alcanza su mayor apogeo en el siglo XVIII, bajo la supremacía política y administrativa de Popayán (Colmenares, 1983). Esta dinámica continuará y en cierto modo se profundizará después de la abolición de la esclavitud (1851) y la decadencia de Popayán, cuando Cali asume el papel dominante en toda la región. Entonces se trata de una imagen que siempre ha estado presente en la historia de la ciudad en sus diferentes períodos de su evolución. 
Por otro lado, hay que tener en cuenta la presencia en las últimas cuatro décadas en Cali de grupos mulatos procedentes de la Costa Pacífica del Cauca (municipio de Guapi), que constituyen la "colonia guapireña". A partir de los años sesenta los migrantes de este municipio, pequeño puerto en el Pacífico caucano, paulatinamente han conformado redes familiares en la ciudad de Cali, dotadas de un capital cultural, escolar, económico y social, acumulados por las élites negras y mulatas locales hacia finales del siglo XIX en la explotación de los aluviones auríferos, si bien algunas de ellas son descendientes mulatos de las uniones entre técnicos extranjeros de las empresas europeas y americanas allí instaladas hacia finales del siglo XIX y comienzos del XX y mujeres negras nativas. Los capitales de los guapireños aplicados en Cali han permitido el desarrollo de un empresariado en actividades que combinan los pequeños y medianos negocios con las prácticas culturales (restaurantes con productos del Pacífico, música, danza, etc., véase Urrea y Mejía, 2000). Se trata de una clase media negra mestizada con sus descendientes nacidos en Cali, compuesta por profesionales y empresarios bien integrados, a nivel residencial, cultural y social, que ha podido interactuar con clases medias blancas y mestizas mediante alianzas económicas y matrimoniales.

Por el contrario, el Departamento del Chocó, la Costa Pacífica de Nariño y en una menor medida, el hinterland rural de Buenaventura, en donde los poblamientos históricos han sido masivamente negros y el mestizaje muy reducido, son percibidos desde el exterior, en particular en Cali, como sociedades "negras" lejanas o apartadas. Los migrantes de estas áreas son en su mayor parte de origen rural $^{20}$ o bajo la modalidad de etapas sucesivas más o menos largas en los barrios pobres de los pequeños centros urbanos de municipios cercanos, con un bajo nivel de capitales de llegada a Cali, lo cual se traduce en una fuerte concentración residencial en los barrios más precarios, en los que pesa el estigma de "ghettos" y "barrios de negros".

Se tiene entonces, entre las poblaciones negras y mulatas que residen en Cali y la sociedad mestiza local, una distancia cultural y social recíproca que varía según el origen migratorio y determina, a su vez, prácticas y percepciones del racismo diferentes. Este esquema permite explicar los grados crecientes de percepción de la discriminación racial por los migrantes, desde los orígenes geo-culturales más cercanos (Costa Pacífica del Valle y Norte del Cauca) hasta los más lejanos (Costa Pacífica de Nariño y Chocó). En cambio, no explica los niveles relativamente altos de percep- 
ción de la discriminación entre los migrantes del interior del Valle, de la Costa Pacífica del Cauca y de Nariño, y sobre todo, de los migrantes de Buenaventura y algunos afrocolombianos nativos de Cali.

2. Una segunda explicación pone en relación los niveles de percepción del racismo con las condiciones de inserción socioeconómica de unos y otros, y las dificultades que encuentran sus perspectivas y estrategias de ascenso social. Ella concierne tanto a los nativos como a los migrantes. En los otros análisis de los datos de la encuesta se mostró que las desigualdades más fuertes de condiciones de vida en Cali afectan a los hogares afrocolombianos de clase media. En estos estratos socioeconómicos los indicadores de hacinamiento en la residencia y el acceso a los servicios y bienes de consumo revelan las mayores disparidades en contra de la población negra y mulata (Bruyneel y Ramírez, 1999: 56-61). Se llega a una conclusión similar a través de la comparación en los niveles de desempleo y en las estructuras socio-ocupacionales (Quintín, Ramírez y Urrea, 2000). Además, el origen geográfico es un factor importante de diferenciación socioeconómica de las poblaciones negras y mulatas de Cali, como ya fue anotado antes. En efecto, el contraste es muy fuerte entre las estructuras socio-ocupacionales que se observan entre los migrantes de Buenaventura o del interior del Valle del Cauca, de la Costa Pacífica del Cauca y sus descendientes nacidos en Cali, las cuales testimonian una inserción económica satisfactoria, y las de los originarios de la Costa Pacífica de Nariño y del Departamento del Chocó (migrantes y sus descendientes nacidos en Cali) que presentan al contrario una fuerte marginalización. En forma de ejemplo, la proporción de mujeres económicamente activas que trabajan como empleadas domésticas son $25 \%$ y $12 \%$ para los dos primeros orígenes mientras que aumentan al $41 \%$ y $37 \%$ para los segundos. Igualmente, los hombres activos que ocupan empleos no calificados son solamente el $11 \%$ del total en los primeros contra el $19 \%$ y $20 \%$ en los segundos. Las percepciones de las discriminaciones obedecen así a lógicas distintas. Esquemáticamente podría decirse que los originarios de Buenaventura, en su mayor parte clases medias, reaccionan más frente a la existencia de frenos específicos a la inserción económica y social que la gente negra y mulata, tales como acceso más difícil a la educación, discriminación en los enganches o en la promoción laboral, arbitrariedad policial, etc., que ellos perciben como obstáculos discriminatorios a sus expectativas de ascenso social. Por el contrario, los de la Costa Pacífica de Nariño y del Departamento 
del Chocó denuncian más moderadamente el origen racial de la exclusión residencial y ocupacional de que son víctimas, ya que tienen el sentimiento de compartir, en igualdad con las poblaciones blancas y mestizas en los barrios precarios donde todos residen, el reducido capital económico y social de que disponen.

3. El tercer factor nos introduce nuevamente en la cuestión de la segregación residencial y a la dimensión socio-espacial de la discriminación. Hay que volver a los fuertes nexos que existen en Cali entre lugar de residencia, origen migratorio y características fenotípicas de la población. Aunque en este artículo no presentamos análisis estadísticos (índices de disimilaridad o índice de Hutchens) para medir la diferenciación espacial de las regiones de residencia y avanzar así en un diagnóstico riguroso sobre los niveles de segregación socio-racial en Cali, la cartografía de los datos del censo y de la encuesta muestran de entrada la desigualdad en la distribución de los lugares de residencia (ver mapa 2 y, para análisis más detallados, los capítulos 2y 4 en Barbary et alli, 1999b). Se observa en particular que los migrantes de la Costa Pacífica de Nariño, del Chocó, y sus descendientes nacidos en Cali, tienen una localización residencial muy concentrada en los barrios más pobres en el Oriente de la ciudad (ibid, pp. 13-14), el Distrito de Aguablanca (comunas 13,14 y 15) y en las comunas 6,7 y 21 , donde se encuentra la mayor proporción de hogares afrocolombianos y personas de fenotipo negro (respectivamente de 35 a $46 \%$ y de 18 a $27 \%$ en promedio por sector cartográfico del censo, si bien localmente estas concentraciones pueden ser más elevadas, ver mapa 2 y ibid., pp.38-40). Comparados a los promedios para el conjunto de la ciudad $-30 \%$ de hogares afrocolombianos y $25 \%$ de la población negra o afrocolombiana- dichas cifras no permiten atestar para nada la existencia de un ghetto racial en Cali. ${ }^{21}$ Sin embargo, la marginalización económica y social de estos barrios por la pobreza, el desempleo masivo, el menor acceso a la infraestructura de servicios públicos, la delincuencia, etc. es una realidad incuestionable.

Complementando los datos estadísticos, los datos antropológicos permiten acercarse a las mediaciones simbólicas entre los actores involucrados: la población negra y mulata, concentrada en determinados barrios en donde representa una proporción importante de la población, a veces mayoritaria, genera en las percepciones externas a estos barrios, según ya fue advertido, la imagen de "barrios de negros". Como reacción a este proceso se construye muchas veces en estos mismos barrios una identidad que valoriza 


\section{Mapa 2}

Proporción estimada de hogares afrocolombianos por sectores cartográficos en Cali

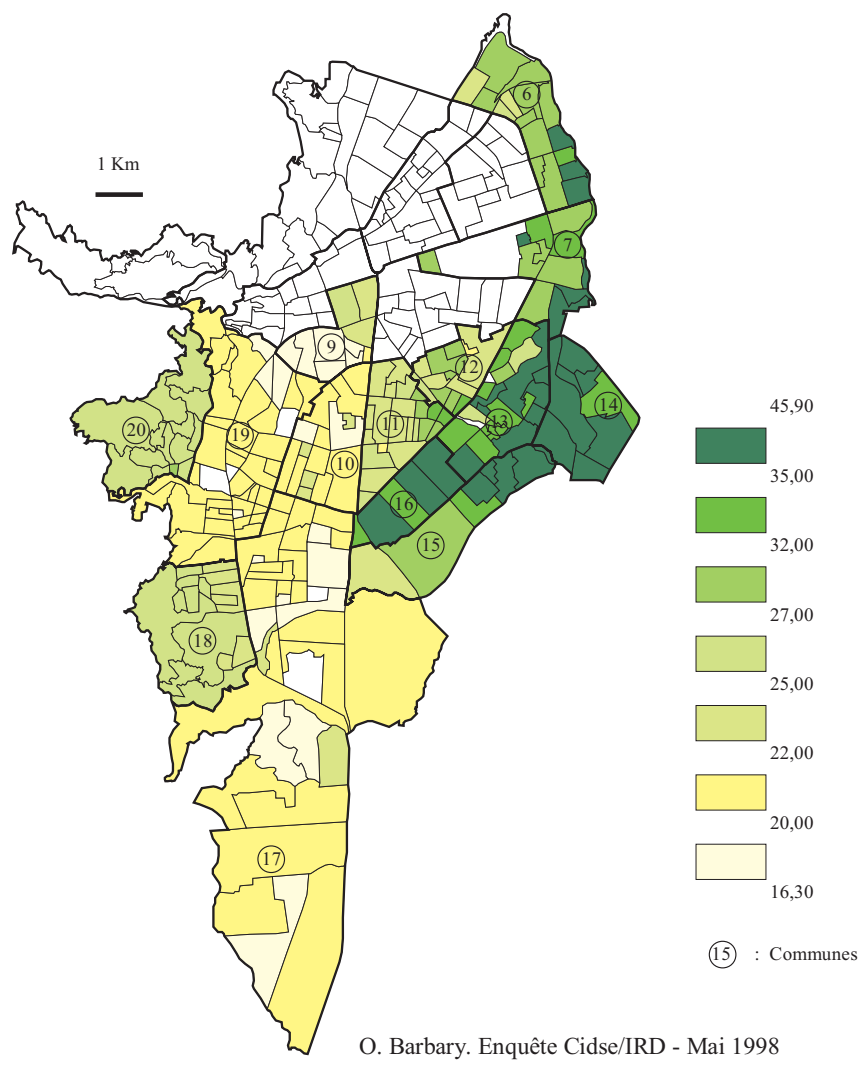

una "personalidad racial". De otro lado, cierto léxico a menudo traído de contextos sociales muy distintos, que traduce las separaciones simbólicas entre unos barrios y otros, ha fundado en varias dimensiones de la vida cotidiana la percepción de la segregación espacial, social y racial. Por ejemplo, aunque la realidad de la segregación en Cali no presenta una medida similar con las modalidades que prevalecen en las grandes metrópolis estadounidenses, la noción de "ghetto" es objeto de uso generalizado en una serie de barrios del Distrito de Aguablanca, siendo reapropiado y resignificado por los jóvenes afrocolombianos, quienes así expresan su per- 
cepción de los resultados de la segregación residencial. El término "ghetto" atraviesa así las fronteras nacionales vía los medios de comunicación, ya sea en los contenidos de denuncia del movimiento negro americano o a través de las músicas de reaggae o rap. Las dos facetas, racial y de clase social, que interactúan una sobre la otra, son el soporte de la estigmatización del Distrito de Aguablanca, al tiempo que juegan un papel de autorepresentación: son la clave en la producción de la alteridad en estas áreas urbanas. Ellas permiten explicar el porqué las personas que proceden de la Costa Pacífica de Nariño y del Departamento del Chocó, y que están sobre representadas demográficamente en el Distrito de Aguablanca, perciban la discriminación de una manera más aguda que otras poblaciones negras y mulatas más repartidas en el conjunto de la ciudad, como por ejemplo las de orígenes de la Costa Pacífica del Cauca y Norte del Cauca.

\section{Conclusión}

Los resultados del enfoque neo-étnico implementado en el censo de 1993, en perfecta coherencia con los datos más finos de sociólogos y antropólogos, ponen de relieve la existencia, en la región del Pacífico, de una afirmación de pertenencia a la "comunidad negra" basada en un principio étnico-territorial, que se podría calificar de "utilitario" en la medida en que se encuentra instrumentalizado social y políticamente por un gran número de actores. El análisis de los datos censales demuestra en todo caso que el modelo de identidad propuesto por la Ley 70 tuvo un impacto importante, capaz de promover localmente una pertenencia colectiva a las "comunidades negras". Sin embargo, no se debe sacar de esta realidad una visión demasiado estereotipada de la nueva identidad afrocolombiana en el Pacífico. Como lo expresa Hoffmann en su estudio de las movilizaciones identitarias en la costa del Departamento de Nariño:

de manera general, las categorías elaboradas por la "gente de los ríos" en torno a la cuestión identitaria son, a menudo, más matizadas y flexibles que las categorías propuestas por los intelectuales y dirigentes del movimiento negro (cf. por ejemplo las combinaciones de criterios fenotípicos, residenciales, de parentesco y de prácticas sociales para definir quien es miembro de un territorio, y por lo tanto "negro"). Más que una contradicción, este desfase es el producto de condicionantes externos por el momento insuperables: los dirigentes no pueden más que situarse en los marcos de pensamiento elaborados en otros contextos (en la ciudad de 
Bogotá y en otros centros urbanos, en los medios políticos) que exigen enfatizar en los particularismos y conducen así a una interpretación "esencialista" de las realidades sociales, culturales, económicas y políticas de las poblaciones involucradas, mientras que, en la base, las experiencias cotidianas de coexistencia incitarían más bien a la flexibilidad y a la negociación. (Hoffmann, 2000a:50)

Por otro lado, de la encuesta realizada en Cali en 1998, se puede concluir que la auto-afirmación fenotípica de las poblaciones afrocolombianas en esta ciudad funciona de manera radicalmente distinta, antes que todo en relación estrecha con las categorías raciales de uso común (y utilizadas por los encuestadores), las divisiones y fronteras subyacentes a éstas, y los estigmas o, al contrario, las connotaciones positivas que estas categorías conllevan según los contextos. Si bien otros determinantes existen, como son el origen migratorio, la edad, la categoría socio-profesional, el lugar de residencia o el sexo, sólo actúan en segundo rango. Parecería entonces que la construcción de la identidad "negra" en Cali es independiente de las disposiciones previstas en la Ley 70 y del proceso socio-político que conduce a su adopción. En esto ella se diferencia claramente de la identidad étnico-territorial en la región del Pacífico, por lo tanto, el marco interpretativo de esta última a la luz de las implicaciones sociales y políticas de la Ley (Agier y Hoffmann, 1999; Hoffmann, 2000a) debe ser modificado para dar cuenta de manera pertinente del avatar urbano de la nueva identidad afrocolombiana. En la ciudad, esta última aparece a la vez más compleja y endógena en su elaboración.

En el espacio urbano caleño (ver Mapa 2 en la presentación al número de la revista) entran en juego en la construcción identitaria otras lógicas diferentes a las territoriales "rurales" (Quintín, Ramírez y Urrea, 2000). En lugar de una referencia comunitaria de pertenencia, mediante la cual hay una relativa homogeneidad sociocultural y socioeconómica con un fuerte sentido de adscripción local, en los sectores más pobres de la ciudad, donde hay la mayor concentración de población negra (diversos barrios del Distrito de Aguablanca), opera una construcción territorial segmentada bipolar: desde "adentro" aparece la figura inventada por los jóvenes raperos, a través de los circuitos transculturales del reggaey del hip hop desde los años ochenta, del ghetto, mientras desde "afuera" (desde los barrios en donde residen supuestamente los otros, los "blancos", los "mestizos") se maneja la figura de "barrios de negros" (Urrea y Murillo, 1999). Curiosamente no hay una separación muy clara entre unos y otros barrios en el mismo Distrito 
de Aguablanca o con otras áreas urbanas colindantes, además porque el mestizaje es generalizado en todas las áreas (Barbary et alii, 1999b; Urrea y Quintín, 2000). Esto demuestra que las condiciones de vida urbana con un alto componente de exclusión en los sectores populares negros, relacionado con las percepciones fenotípicas, son el soporte de la construcción de identidades racializadas, pero a través de un contexto de clases sociales: el ghetto es de gente "pobre" y "negra", al tiempo que desde los otros lugares se califica de "negra" la población de esos barrios; pero además porque en los "barrios de ricos viven los blancos", de acuerdo a la percepción vivida por la "gente del ghetto".

En otros términos, el color de piel, o más bien sus consecuencias en términos de segregación de los espacios urbanos, juegan sin duda alguna un papel más importante que en la región del Pacífico. En efecto, podemos considerar que la discriminación socio-racial atraviesa las desigualdades de clase y profundiza otras formas de discriminación (de género, por edad, orientación sexual, etc.). Por esta razón, como ya lo hemos dicho, más que la transferencia de una identidad étnico-territorial desde la región de origen, la construcción de la identidad "negra" en Cali parece responder a la necesidad de la población afrocolombiana a enfrentar a distintos tipos de discriminaciones y desigualdades en el acceso a los diferentes mercados urbanos; en suma, a una reivindicación de ciudadanía y de igualdad de oportunidades.

\section{Notas}

1. Urrea, Ramírez y Viáfara (2002, cuadro 1), con base en varias fuentes estadísticas, avanzan la cifra entre $20 \%$ y $22 \%$ como promedio nacional en junio del 2001. En diciembre del 2000, la encuesta nacional de hogares realizada por el DANE (Departamento Administrativo Nacional de Estadística, etapa 110) en las catorce primeras ciudades del país arroja un estimado del 17,9\% de la población en esas ciudades que se identifica de color de piel negra o morena con una pregunta, de auto identificación de su color de piel por el encuestado a través de 4 fotografías. Urrea, Ramírez y Viáfara (op. cit.) presentan estimativos adicionales para otras regiones de Colombia, incluyendo las costas Pacífica y Caribe, que aumentan ligeramente el porcentaje entre $20 \%$ y $22 \%$ para el total de la población colombiana.

2. Uno de los aspectos importantes de los debates actuales sobre la población afrocolombiana se centra en cómo devolverle su visibilidad en el sistema estadístico nacional (ver al respecto, Barbary [2001], pp. 774-788; al igual que en Urrea, Ramírez y Viáfara, en la parte introductoria y conclusiones, op.cit.). 
3. Sobre los procesos de estructuración política de la población negra, ver por ejemplo J. Arocha (1992), C.E. Agudelo (1998), M. Agier \& O. Hoffmann (1998), N. S. De Friedemann (1998), C. E. Agudelo, O. Hoffmann \& N. Rivas (1999).

4. El equipo lo conformaron, por parte del CIDSE (Centro de Investigación y Documentación Socioeconómica de la Facultad de Ciencias Sociales y Económicas de la Universidad del Valle, Cali): de F. Urrea (Sociólogo), P. Quintin (Antropólogo) y H. F. Ramirez (Estadístico). Por parte de IRD (Institut de Recherche pour le Développement, Paris): de M. Agier (Antropólogo), O. Barbary (Estadístico) y O. Hoffmann (Geógrafa).

5. En 1993, la pregunta censal fue: “¿Pertenece usted a alguna etnia, grupo indígena o comunidad negra? ¿A cuál?”. En 1918 fue el último censo que incluyó identificación racial de la población; por supuesto, en esa época que naturalizaba todavía la "raza", con un modelo en el cual las categorías (negro, blanco, indio, mestizo) no fueron discutidas... ni eran discutibles. Sin embargo, dado la metodología de "autoempadronamiento" empleada entonces, la pregunta fue autoadministrada. En 1918, el 11\% de las personas que contestaron se declararon de raza negra y el $8,5 \%$ de raza india (DANE 2000, Análisis de resultados, pp. 60,61).

6. Por el contrario, han salido elegidos concejales negros dentro de listas de los partidos tradicionales y con banderas populares o de clases medias, pero sin ninguna alusión a la cuestión racial.

7. En la encuesta CIDSE/IRD de 1998, los encuestadores y encuestadoras formulan al encuestado (o encuestada) la pregunta: “¿Cuál es su color de piel?”.

8. Esta región se entiende aquí como los municipios de la costa Pacífica de los departamentos del Valle del Cauca, Cauca y Nariño, y la totalidad del Departamento del Chocó.

9. En muchos otros contextos urbanos nacionales o de otros países, caracterizados por crecientes consumos culturales, es también frecuente que determinados fenómenos transculturales como lo es el rapy la cultura hip hop, den lugar a representaciones del territorio urbano en las que se denuncian las características segregativas de ciertos barrios.

10. Este modelo no permite descartar eventuales interacciones (se rechaza la hipótesis de interdependencia entre las variables). Pese a todo, el ajuste de las frecuencias marginales es satisfactorio (la desviación típica de los residuos es del 8\%). En cambio, la hipótesis de independencia se admite para el modelo que integra todas las interacciones de orden 2 (ausencia de interacciones de orden superior), del que comentamos ciertos resultados.

11. Preparatoria para la expedición de la Constitución de 1991 y que operó en ese mismo año.

12. En el Ministerio del Interior, opera la División de Negritudes, paralela a la de Pueblos Indígenas; a escala departamental (Valle del Cauca) y municipal (Cali), las divisiones de "minorías étnicas o indígenas y negritudes". Estas últimas dependen de las Secretarías de Desarrollo Social o de Bienestar Social. Por otra parte, en algunos Ministerios (especialmente en Educación, Salud y Medio Ambiente), existen programas focalizados para grupos étnicos.

13. Para una definición precisa de esta variable, ver Barbary et alii (1999:10-11). 
14. De todas formas, hay que señalar que el referente cultural en el cual se sostiene le construcción de la negritud en Cali no viene en su mayor parte del Africa sino precisamente del mundo cultural norteamericano, a través de sus héroes deportivos negros, de sus músicos y actores de cine, y de la moda y las formas corporales de presentación, generalizadas entre los distintos grupos sociales negros de los Estados Unidos. De este último país y de Sudáfrica, provienen también las imágenes políticas de lucha contra el racismo, como puede observarse en las peluquerías "Afro" de Cali y Buenaventura: fotos de Nelson Mandela, Malcom X, Martin Luther King, al lado de jugadores famosos de la NBA y de raperos norteamericanos.

15. Así, valdría la pena, para profundizar el análisis, repetir el ejercicio de modelisación juntando las dos respuestas "negra" y "morena”, asumiendo la hipótesis inversa que en los contextos barriales el uso de las dos expresiones es intercambiable en su contenido.

16. Sin embargo, existen efectos cruzados significativos (con probabilidad superior al 95\%), que muestran que las características del encuestador juegan de manera específica para las subpoblaciones caracterizadas como "negras" o "mulatas". Así, entre la población negra, los encuestadores (hombres) afrocolombianos obtuvieron una declaración de color de piel negra superior al promedio (68\% vs. $57 \%)$, mientras que en la población mulata, son las encuestadoras afrocolombianas quienes obtienen esta sobre-declaración (18\% vs. $12 \%)$; al contrario, las encuestadoras no-afrocolombianas registran una sub-declaración del fenotipo negro (7\% vs. $12 \%)$. Pero a estas alturas, hay que advertir que el tamaño de la muestra es demasiado pequeño para autorizar el control riguroso de todos los factores que pueden influir; por lo tanto estos resultados no son de fácil interpretación; en todo caso, no permiten sostener una hipótesis opuesta a la que aquí defendemos.

17. La desviación típica de los residuos es del 8\%, exceptuando cuatro celdas muy mal ajustadas debido a efectivos muy reducidos.

18. Para asegurarse de ello, habría que probar este efecto cruzado en un modelo que integre la edad, la categoría socio-profesional y el origen migratorio, pero, nuevamente, se alcanzarían los límites permitidos por el tamaño de la muestra.

19. Se ubican entre $55 \%$ de respuestas correctamente previstas para la discriminación en los hospitales y centros de salud y $62 \%$ para la discriminación en los transportes y en el barrio. El último modelo explica mejor la declaración de una experiencia personal de discriminación (70\% de previsiones exactas).

20. En cambio, no es necesariamente el caso de los migrantes del Departamento del Chocó en Medellín y Bogotá, ya que una buena parte de ellos proviene de la ciudad de Quibdó y otros centros urbanos de ese Departamento, con mejores capitales adquiridos y por lo mismo con un acceso mejor en dichas ciudades. Es decir, hay también una gran heterogeneidad de la migración chocoana al interior del país, incluyendo la ciudad de Cali, ya que también aquí han llegado capas medias de las zonas urbanas chocoanas, aunque en menor peso que las de procedencia rural.

21. La encuesta CIDSE-Banco Mundial de 1999 arrojó un 37\% de hogares afrocolombianos y cerca del $32 \%$ de población negra/mulata; la encuesta nacional de hogares del DANE de diciembre del 2000 , etapa 110 , un $26.5 \%$ de población autopercibida como negra/mulata. Esto significa que entre estos valores se ubica la población afro- 
colombiana en Cali, pero con presencia de una población mestiza en forma generalizada aún en los barrios con mayor concentración de población negra.

\section{Bibliografía}

AGIER, M.; BARBARY O.; HOFFMANN, O.; QUINTIN, P.; RAMIREZ, H. F., y URREA F. (2000). "Espacios regionales, movilidad y urbanización, dinámicas culturales e identidades en las poblaciones afrocolombianas del Pacifico sur y Cali. Una perspectiva integrada”. Informe final para COLCIENCIAS, Cidse/IRD, Cali, 88p.

AGIER M., y HOFFMANN, O. (1998). "Les terres des communautés noires dans le Pacifique colombien, Interprétations de la loi et stratégies d'acteurs". Problèmes d'Amérique Latine, $\mathrm{n}^{\circ}$ 32, Paris, pp. 17-42.

AGUDELO, C. (1998). "Cambio constitucional y organización política de las poblaciones negras en Colombia”. Proyecto: Organización social, dinámicas culturales e identidades de las poblaciones afrocolombianas del pacífico y suroccidente en un contexto de movilidad y urbanización. (Movilidad, urbanización e identidades de las poblaciones afrocolombianas, título resumido). Documento de Trabajo $\mathrm{n}^{\circ} 26$, Universidad del Valle, Cali, fotocop, $28 \mathrm{p}$.

AGUDELO, C.; HOFFMANN, O., y RIVAS, N. (1999). "Hacer política en el Pacífico sur, algunas aproximaciones". Documentos de Trabajo del CIDSE, $\mathrm{n}^{\circ} 39$, Proyecto CIDSE-IRD, Cali, 83 p.

AROCHA, J. (1989). "Hacia una Nación para los Excluidos". Magazín Dominical, El Espectador, nº 329, pp. 14-21, Bogotá.

AROCHA, J. (1992). "Los negros y la nueva constitución colombiana de 1991”. América Negra, $\mathrm{n}^{\circ}$ 3, Pontificia Universidad Javeriana, Bogotá.

AROCHA, J. (1999). Ombligados de Ananse. Hilos ancestrales y modernos en el Pacífico colombiano, U. Nacional-CES, 204p, Bogotá.

BARBARY, O. (1998). Cuestionario de la encuesta "Movilidad, urbanización e identidades de las poblaciones afrocolombianas", título resumido. "Organización social, dinámicas culturales e identidades de las poblaciones afrocolombianas del pacífico y suroccidente en un contexto de movilidad y urbanización", título original. Universidad del Valle. Cali, 32 p.

BARBARY, O. (2001). "Mesures et réalités de la segmentation socio-raciale à Cali: une enquête sur les ménages afro-colombiens”. Population, vol. 56, $\mathrm{n}^{\circ}$ 5, pp. 773-810, Paris.

BARBARY, O.; RAMIREZ, H. F., y URREA, F. (1999a). Resultados preliminares del análisis de la encuesta (tabulación de la información), Informe de Etapa Cuantitativa $\mathrm{n}^{\circ} 3$, Proyecto "Movilidad, urbanización e identidades de las poblaciones afrocolombianas", Universidad del Valle, Cali, multigr., 530 p.

BARBARY, O.; BRUYNEEL, S.; RAMIREZ, H. F., y URREA, F. (1999b). "Afrocolombianos en el área metropolitana de Cali, estudios sociodemográficos”. Documentos de Trabajo del CIDSE $\mathrm{n}^{\circ}$ 38, Proyecto CIDSE-IRD, Cali, 98p.

COLMENARES, G. (1983). "Cali: terratenientes, mineros y comerciantes. Siglo XVIII”. En Sociedad y Economía en el Valle del Cauca. Tomo I. Bogotá, Banco de la República, Bogotá. 
DANE, (2000). Los grupos étnicos de Colombia, CD-ROM ISSN 0124-437X:

1. El carácter multiétnico de Colombia y sus implicaciones censales

2. Los grupos étnicos de Colombia en el censo de 1993 - Memorias

3. Intentos de cuantificación y criterios, censo 1993

4. Resultados

5. Análisis de resultados

ELIAS, N. (1982). Sociología fundamental. Gedisa, Barcelona.

ELIAS, N. (1991). La Société des individus. Trad. franç., avant-propos de R. Chartier, Fayard, Paris.

FRIEDEMANN, N. de (1974), "Minería del oro y descendencia: Güelmambí, Nariño”. Revista Colombiana de antropología, nํ16, pp. 9-86, Bogotá.

FRIEDEMANN, N. de, (1976)."Negros, monopolio de la tierra, agricultores y desarrollo de plantaciones de azúcar en el valle del río Cauca". In Nina de Friedemann (ed.), Tierra, tradición y poder en Colombia: enfoques antropológicos. COLCULTURA, Bogotá.

FRIEDEMANN, N. de, (1984). "Estudios de negros en la antropología colombiana”. In Jaime Arochay y Nina de Friedemann (eds.), Un siglo de investigación social: antropología en Colombia. Publicaciones ETNO, Bogotá.

FRIEDEMANN, N. de, (1985). "Troncos" among black miners in Colombia". In Thomas Greavea y William Culver, Miners and mining in the America. (eds.), Manchester University Press, Manchester.

FRIEDEMANN, N. de (1998). Le rôle de l'Afrique et des Noirs dans la construction de l'Amérique. La chaîne et le lien, Une vision de la traite négrière, pp. 383-394, UNESCO, Paris.

FRIEDEMANN, N. de y AROCHA, J. (1986), De sol a sol: génesis, transformación y presencia de los negros en Colombia, Planeta editores, Bogotá.

FRIEDEMANN, N. de y ESPINOSA, M. (1993). "La familia minera en el litoral Pacífico”. In Pablo Leyna (ed.), Colombia Pacífico, Vol. II, 560-569, Editorial del Fondo FEN, Bogotá.

GUTIÉRREZ DE PINEDA, V. (1968.) Familia y cultura en Colombia. Tercer Mundo y Universidad Nacional de Colombia, Bogotá.

HOFFMANN, O. (2000a), "Jeux de parole et de mémoire autour des mobilisations identitaires (Colombie)", Autrepart n ${ }^{\circ}$ 14: Logiques identitaires, logiques territoriales, Paris, L'aube - IRD, pp. 33-51.

HOFFMANN, O. (2000b). "Espacios, movilidad y región en el Pacífico sur”. In Espacios regionales, movilidad y urbanización, dinámicas culturales e identidades en las poblaciones afrocolombianas del Pacífico sur y Cali. Documento de Trabajo Cidse, $\mathrm{n}^{\circ}$ 52, Cidse-Ird, Universidad del Valle, Cali, 89 p.

HURTADO, T. (2000). “Treinta años de protesta social: El surgimiento de la movilización étnica afrocolombiana en el Norte del Cauca”. Documento de Trabajo $\mathrm{n}^{\circ} 50$, CIDSE-IRD, Universidad del Valle, Cali, pp. 105-138.

MOTTA, N. (1975). Estratificación social en Salahonda, Tesis Licenciatura de Antropología, Universidad del Cauca, Popayán. 
MOTTA, N. (1993). "Mujer y familia en la estructura social del Litoral Pacífico”. Revista Colombiana de Trabajo Social, n 6, pp. 57-76, Cali.

QUINTÍN, P.; RAMÍREZ, H. F. y URREA, F. (2000). Relaciones interraciales, sociabilidades masculinas juveniles y segregación laboral de la población afrocolombiana. Documento de trabajo n ${ }^{\circ}$, CIDSE-IRD, Universidad del Valle, Cali, 83p.

SIMON, P. (1998). "Nationalité et origine dans la statistique française Les catégories ambiguës." Population, n³-1998, Paris, pp. 541-568.

URREA, F., y HURTADO, T. (1997). "Puerto Tejada: de núcleo urbano de proletariado agroindustrial a ciudad dormitorio". In Francisco Zuluaga (ed.) Puerto Tejada. 100 Años, Municipio de Puerto Tejada, Alcaldía Municipal, Cali, pp.197-242.

URREA, F., y MURILLO, F. (1999). “Dinámica del poblamiento y algunas características de los asentamientos populares con población afrocolombiana en el oriente de Cali”. In F. Cubides y C. Domínguez (eds.) Desplazados, migraciones internas y reestructuraciones territoriales. CES-Universidad Nacional, Bogotá, pp.337-405.

URREA, F.; ARBOLEDA, S., y ARIAS, J. (2000). "Redes familiares entre migrantes de la costa pacífica a Cali”. Revista Colombiana de Antropología, vol. 35, enero-diciembre, ICANH, Bogotá, pp.180-241.

URREA, F., y MEJIA, C. A. (2000). "Innovación y cultura de las organizaciones en el Valle del Cauca”. In F. Urrea, L.G. Aranho, C. Davila, C.A. Mejia, J. Parada y C.A. Bernal. Innovación y cultura de las organizaciones en tres regiones de Colombia. Colciencias, Corporación Calidad, Ediciones Tercer Mundo, Bogotá.

URREA, F., y QUINTÍN, P. (2000). "Modelos y fisuras de la masculinidad entre jóvenes negros de sectores populares en la ciudad de Cali”. In VV.AA., Relaciones interraciales, sociabilidades masculinas juveniles y segregación laboral de la población afrocolombiana en Cali. Documento de Trabajo n 49, CIDSE-IRD, Universidad del Valle, Cali, pp.36-53.

URREA, F.; RAMÍREZ, H.F., y VIÁFARA, C. (2002). “Perfiles sociodemográficos de la población afrocolombiana en contextos urbano-regionales del país a comienzos del siglo XXI". Ponencia presentada en el simposio "Estado del arte de los estudios afrocolombianos", organizado por la especialización de "Estudios Afrocolombianos", de la Universidad del Cauca, Popayán, Noviembre, 65 ps.

URREA, F., y HURTADO, T. (2002). "La construcción de las etnicidades en la sociedad colombiana contemporánea: un caso ejemplar para la discusión sobre etnicidad y grupos raciales". In Interculturalidad y política: desafios y posibilidades. Editora Norma Fuller. Red para el Desarrollo de las Ciencias Sociales en eu Perú, Lima, pp. 165-199.

VELÁSQUEZ, R. (1953). Memorias del odio. Bogotá. Alianza de Escritores Colombianos, Bogotá.

VELÁSQUEZ, R. (1957). "La medicina popular en la Costa Colombiana del Pacífico”. Revista Colombiana de Antropología, vol. VI, Bogotá.

VELÁSQUEZ, R. (1961). "Ritos de la muerte". Revista Colombiana de folklore, 2(6):9-74; Bogotá.

WADE, P. (1997). Blackness and race mixture. The dynamics of racial identity in Colombia, John Hopkins University Press, Baltimore/London, Traducción española 
Identidad y ciudadanía afrocolombiana en la Región Pacífica y Cali...

(1993). Gente negra, Nación mestiza. Dinámicas de las identidades raciales en Colombia. Bogotá: Ediciones Uniandes-Universidad de Antioquia-ICAN-Siglo de Hombre Editores, Bogotá.

ZAPATA OLIVELLA, M. (1967). "Aportes materiales y sicoafectivos del negro en el folklore colombiano". Boletín cultural de la biblioteca Luis Angel Arango, 10(6), Bogotá. 